\title{
MANIFESTATION OF FAULT ZONES IN GEOPHYSICAL FIELDS
}

\author{
A. A. Spivak \\ Institute of Geosphere Dynamics RAS, Moscow, Russia
}

\begin{abstract}
Geophysical fields influenced by tectonics faults were observed, and instrumental observation results are analysed in the article. It is shown that fault zones are characterized by geophysical fields that are more variable than those in midmost segments of crustal blocks, more intense responses to weak external impacts such as lunar and solar tides and atmospheric pressure variations, and intensive relaxation. Transformation of energy between geophysical fields varying in origin takes place mainly in the fault zones.
\end{abstract}

Key words: geodynamics, tectonic fault, rocks, seismic noise, electric field, magnetic field, radon emanation.

Recommended by K.Zh. Seminsky

Citation: Spivak A.A. 2014. Manifestation of fault zones in geophysical fields. Geodynamics \& Tectonophysics 5 (2), 507-525. doi:10.5800/GT-2014-5-2-0138.

\section{ПРОЯВЛЕНИЕ РАЗЛОМНЫХ ЗОН В ГЕОФИЗИЧЕСКИХ ПОЛЯХ}

\author{
А. А. Спивак \\ Институт динамики геосфер РАН, Москва, Россия
}

\begin{abstract}
Аннотация: Приведен анализ результатов инструментальных наблюдений за геофизическими полями в зонах влияния тектонических разломов. Показано, что разломные зоны характеризуются существенно более высокими по сравнению с серединными участками структурных блоков земной коры вариациями геофизических полей, интенсивным откликом на слабые внешние воздействия в виде твердого лунно-солнечного прилива и барических вариаций атмосферы, а также интенсивностью релаксационных процессов. Преимущественно в разломных зонах наблюдается трансформация энергии между геофизическими полями разной природы.
\end{abstract}

Ключевые слова: геодинамика, тектонический разлом, горные породы, сейсмический шум, электрическое поле, магнитное поле, радоновые эманации.

\section{1. ВВЕДЕНИЕ}

Значительный интерес к изучению разломных зон связан с их важной ролью в формировании напряженно-деформированного состояния земной коры, режима подземных флюидов, а также с повышенной интен- сивностью массо- и энергообменных процессов в зонах их влияния. Сложное внутреннее строение разломных зон, отличающееся повышенной трещиноватостью (раздробленностью) горных пород и, как следствие, их повышенная деформируемость и флюидопроницаемость [Spivak, Tzvetkov, 2009; Seminsky, 2012] 
определяют существенную роль дизъюнктивных нарушений в межгеосферных взаимодействиях и эволюции литосферы в целом.

Практический аспект исследования разломных зон продиктован необходимостью устойчивого освоения платформенных территорий с обеспечением их надежной инженерной защиты от нежелательных, а во многих случаях опасных геодинамических явлений и процессов как природного, так и техногенного происхождения. Особое значение эти работы приобретают в настоящее время в связи с необходимостью строительства новых АЭС и освоения месторождений углеводородов, расположенных в районах со сложными тектоническими условиями.

Несмотря на достаточно большое количество работ, посвященных определению внутренней структуры и свойств разломов, ряд вопросов, касающихся, например, достоверного картирования разломов, закамуфлированных осадочным чехлом, определения их внутренней структуры и размеров зон влияния, изучены недостаточно. Представляется перспективным совершенствовать имеющиеся и разрабатывать новые методы картирования разломных зон, а также подходы к определению их свойств и геодинамического состояния на основе использования информации о пространственных и временных вариациях геофизических полей.

Действительно, разломы, как особые геологические объекты, отличающиеся от окружающих горных пород специфической внутренней структурой, фильтрационными свойствами и условиями деформирования, оказывают влияние на формирование режимов практически всех геофизических полей [Spivak, 2010].

Под разломами будем понимать в дальнейшем линейно простирающиеся структуры земной коры в виде динамических зон, характеризующихся выраженными структурными особенностями, повышенными градиентами вертикальных и горизонтальных движений поверхности земной коры, морфологическими признаками на поверхности, например флексурообразными перегибами, а также интенсивными межгеосферными взаимодействиями, повышенными временными вариациями геофизических полей. При этом разломы рассматриваются не как тонкие межблоковые промежутки, а как изометрические области со своей внутренней структурой [Seminsky, 2003] $]^{1}$, деформирование которых вызывает не только сложные по характеру дифференциальные движения, но также преобразование вещества-заполнителя со временем [Spivak, Tzvetkov, 2009].

Традиционно под термином «разлом» часто понимают разрывные нарушения фундамента либо скальных массивов горных пород на поверхности земной коры [Nesmeyanov, 2004], предполагая при этом, что

\footnotetext{
${ }^{1}$ При таком подходе правомернее использовать термин «разломная зона».
}

разломы фундамента не всегда прослеживаются в осадочном чехле [Makarov et al., 2007]. Однако имеются подтверждения тому, что крупные глубинные структуры проявляются также и в осадочном чехле достаточно узкими зонами повышенной трещиноватости и флюидопроницаемости, поэтажными аномалиями геофизических полей и градиентными элементами морфоструктуры и т.д. [Anisimova, Koronovsky, 2007; Nikolaev et al., 2002; Yudakhin et al., 2003; Gorbunova et al., 2002].

Инструментальные исследования разрывных нарушений на платформенных участках земной коры, которые, как правило, характеризуются достаточно мощным осадочным чехлом [Nukolaev et al.; 2002;], свидетельствуют о наличии в большинстве случаев соответствия между разрывными нарушениями фундамента и структурными проявлениями в осадочном чехле [Anisimova, Koronovsky, 2007], что позволяет трактовать структуры осадочного чехла как разломы земной коры.

Таким образом, можно полагать, что измеряемые (как правило, на земной поверхности) геофизические поля подвержены влиянию разломных зон и, следовательно, содержат информацию о степени их контрастности на фоне окружающего массива, а также о размерах зоны динамического влияния.

Следует отметить, что геофизические поля являются важной неотъемлемой составляющей нашей планеты. Помимо традиционно рассматриваемых физических полей - гравитационного, магнитного, теплового и электрического, к геофизическим полям необходимо отнести также поля, сформированные постоянно проявляющимися процессами физической природы, например поле постоянно присутствующих в верхних твердых геосферах микроколебаний (микросейсмическое поле) и поле эманаций подземных газов ${ }^{2}$. Роль геофизических полей как фактора, объединяющего между собой внутренние и внешние геосферы в единую саморегулирующуюся систему, представляется весьма значительной. С помощью геофизических полей осуществляется взаимодействие между Землей и окружающим ее макрокосмосом, между разными геосферами и отдельными областями внутри каждой из них [Adushkin et al., 2006].

Не менее значительной является информационная роль геофизических полей, которые отражают свойства и структуру геосфер, а также пространственные и временные вариации режимов геофизических процессов, что с успехом используется в решении фундаментальных и прикладных задач геофизики, например определении закономерностей поведения внутренних и внешних оболочек Земли [Gokhberg et al., 1988; Sobolev, Demin, 1980], установлении очаговых зон и пред-

\footnotetext{
${ }^{2}$ Полный перечень геофизических полей существенно шире приведенного, он включает также ряд других полей естественного и техногенного происхождения, например радиационное поле, поле деформаций и т.д.
} 


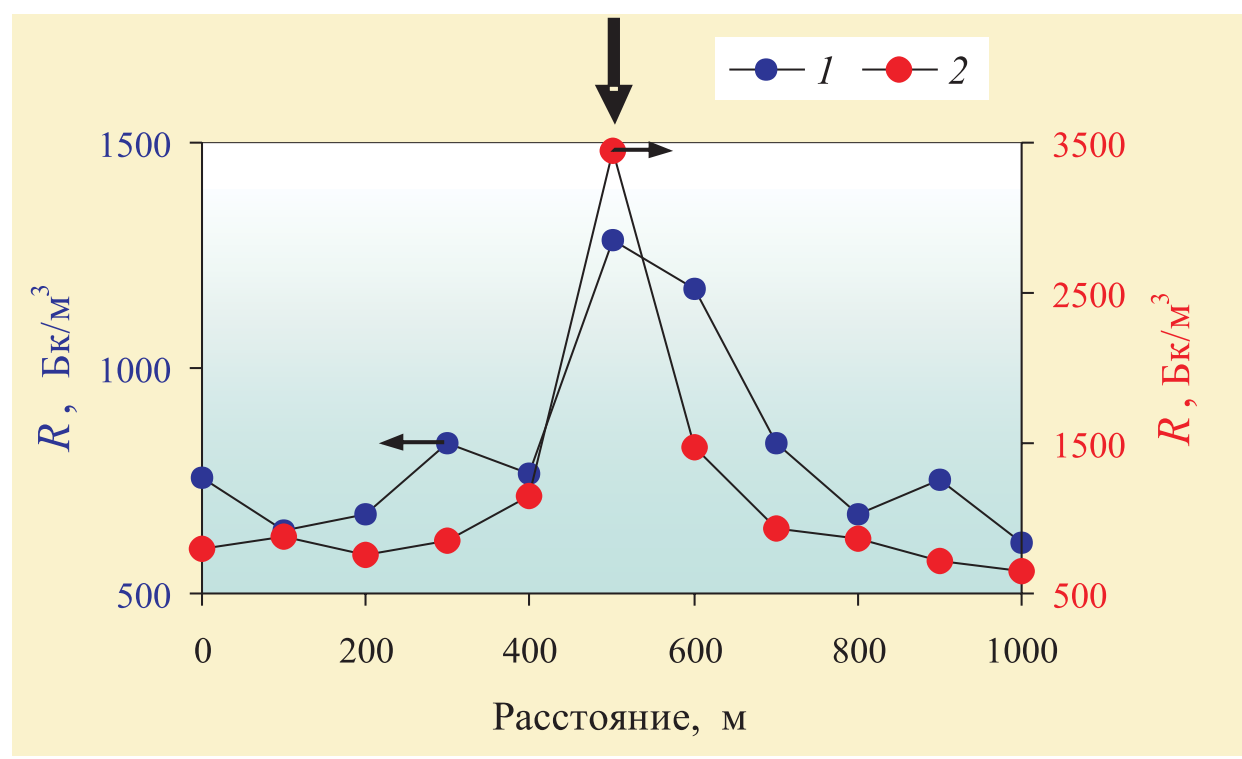

Рис. 1. Объемная активность подпочвенного радона вдоль профилей 1 и 2, пересекающих разломные зоны II порядка относительно Нелидово-Рязанской шовной зоны (вертикальная стрелка - положение центральной части разломных зон).

Fig. 1 . Volume activity of soil radon, $R$ along profiles 1 and 2 across fault zones of the $2^{\text {nd }}$ order in relation to the Nelidovo-Ryazan suture zone (vertical arrows show positions of central parts of fault zones).

вестников землетрясений [Sobolev, 1993; Novik, Ershov, 2001], поиске и разведке полезных ископаемых, описании геодинамической активности локальных участков земной коры и т.д.

В настоящей работе рассматриваются особенности геофизических полей в разломных зонах, а также их вариаций в условиях слабых внешних возмущений в виде лунно-солнечного прилива и барических изменений в атмосфере.

\section{2. ОСОБЕННОСТИ РАДОНОВЫХ ЭМАНАЦИЙ В РАЗЛОМНЫХ ЗОНАХ}

Эманация подземных газов является одним из важнейших процессов, которые позволяют достоверно картировать нарушения сплошности земной коры. Действительно, интенсивность эманаций подземных газов характеризует не только источник, но в значительной мере - фильтрационные свойства земного вещества.

Состав эманирующих газов зависит от конкретного участка земной коры и характеризуется, как правило, наличием $\mathrm{H}_{2}, \mathrm{~N}_{2}, \mathrm{CO}_{2}$, паров воды, а также ряда углеводородных соединений $-\mathrm{CH}_{4}, \mathrm{C}_{2} \mathrm{H}_{6}, \mathrm{C}_{2} \mathrm{H}_{4}$ и других. Характерной особенностью подземных газов является наличие в них небольшого количества изотопов, среди которых особое место занимает изотоп радона ${ }^{222} \mathrm{Rn}$.

Повсеместное распространение радона в земной коре, непрерывность генерации в урансодержащих геологических формациях, а также его особые свойст- ва: невысокая химическая активность, простота регистрации вследствие его радиоактивности, небольшое время полураспада $\left(T_{0}=3.824\right.$ сут $)$ - все это делает его оптимальным индикатором современных геодинамических процессов, протекающих в земной коре. При этом, несмотря на весьма малое содержание радона в общем газовом потоке (около $10^{-16}-10^{-18} \%$ ), интенсивность его эманаций может служить характеристикой эманации и других газов. Последнее связано с механизмом миграции природного радона: весьма обоснованным представляется утверждение, что достаточно тяжелый радон переносится к земной поверхности путем захвата пузырьками водорода и метана.

Вследствие повышенной проницаемости тело разлома представляет собой канал преимущественной миграции подземных флюидов. Потоки подземных газов в зонах разломов существенно превышают фоновые. Величина этих потоков, как и концентрация газов на приповерхностных участках, отражает величину проницаемости каналов миграции [Spivak, Shuvalov, 2011]. На практике для оценки интенсивности газовых эманаций и величины проницаемости разломных зон удобно использовать данные по объемной активности $R$ природного изотопа ${ }^{222} \mathrm{Rn}$ в подпочвенной атмосфере [Seminsky, Bobrov, 2013; Spivak, Kozhukhov, 2004].

Результаты регистрации величины $R$ свидетельствуют о том, что в зонах разломов абсолютная интенсивность газовых эманаций, как правило, в 3-6 раз выше по сравнению с серединными участками структурных блоков (рис. 1) [Spivak et al., 2009]. При этом 


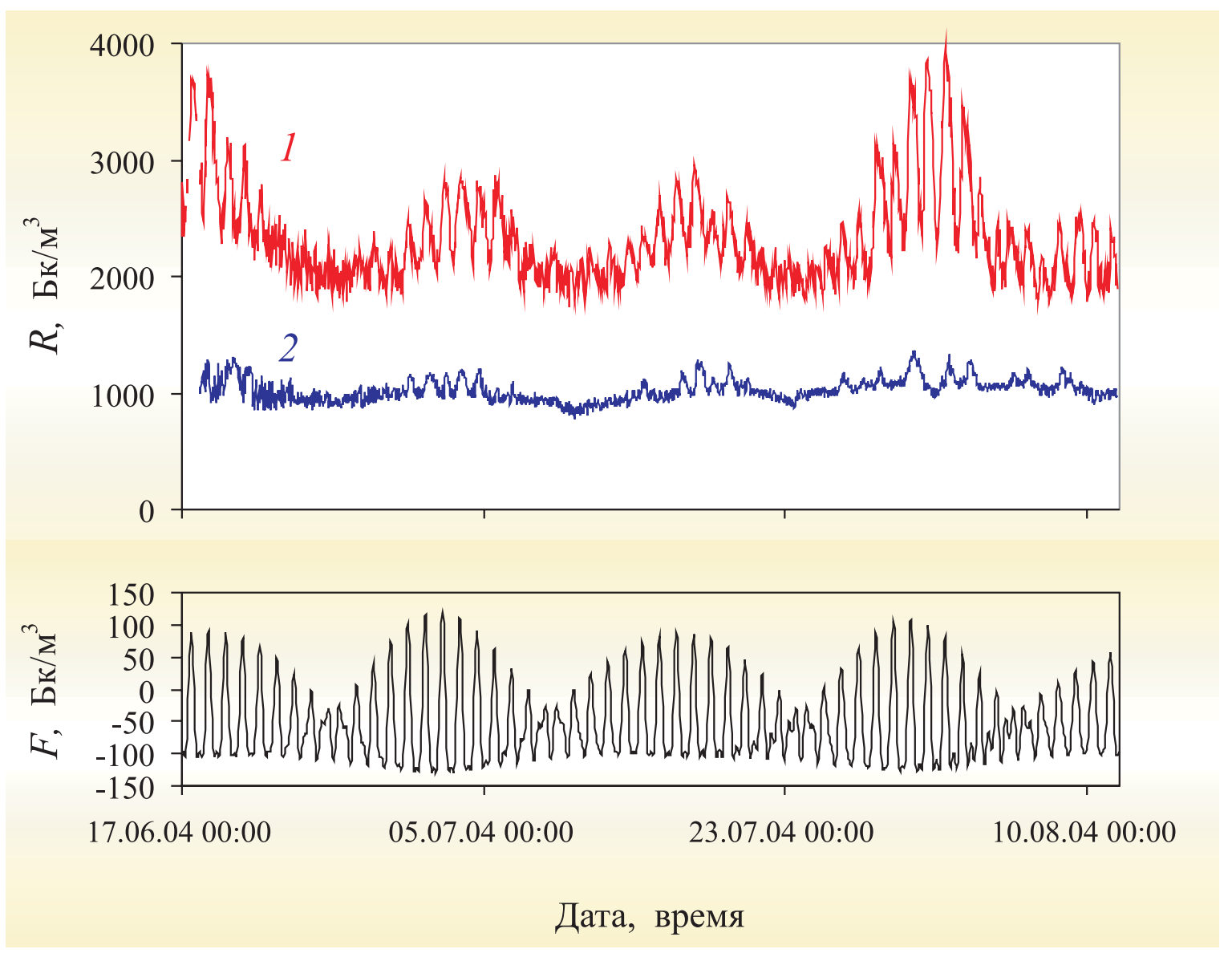

Рис. 2. Верхняя панель: вариации объемной активности подпочвенного радона в пунктах, расположенных на серединном участке разлома II порядка, оперяющего Нелидово-Рязанскую шовную зону, в период высокой стабильности метеоусловий (1) и на серединном участке примыкающего структурного блока (2).

Нижняя панель: вариации приливной силы.

Fig. 2. Top: Variations of volume activity of soil radon, $R$ on sites located in the midmost segment of the $2^{\text {nd }}$ order fault feathering the Nelidovo-Ryazan suture zone.

1 - data for the period of the high stability of weather conditions; 2 - data for the midmost segment of the neighboring structural block. Bottom variations of the tidal force.

относительная величина эманационных аномалий по сравнению с фоновыми значениями объемной активности радона на конкретном участке земной коры может характеризовать степень контрастности разлома, т.е. величину отличия свойств материала-заполнителя разлома от свойств вмещающей среды. Пространственный размер зоны, в которой отмечаются повышенные значения радоновых эманаций, с известным приближением определяет зону влияния разлома.

Однако следует отметить, что повышенная эманация радона является необходимым, но далеко не достаточным условием наличия зоны повышенной проницаемости земной коры. Локальное повышение уровня радоновых эманаций может быть обусловлено не только наличием разломных зон, но также неравномерностью пространственного распределения интенсивности подземных источников радона и разной глу- биной их залегания. Для повышения достоверности картирования разломов необходимо привлекать данные о временных вариациях объемной активности подпочвенного радона, которые вызываются внешними возмущениями, например в виде твердоприливной деформации земной коры или барических вариаций в приземном слое атмосферы [Spivak, Shuvalov, 2011].

Действительно, как показывают результаты инструментальных наблюдений [Spivak et al., 2009], повсеместно наблюдаются ярко выраженные временные вариации величины $R$. При этом указанные вариации характеризуются закономерными периодичностями и цикличностью, которые представлены в последовательном увеличении и уменьшении амплитуды вариаций.

В качестве примера на рис. 2 и 3 приведены результаты регистрации вариаций объемной активности под- 

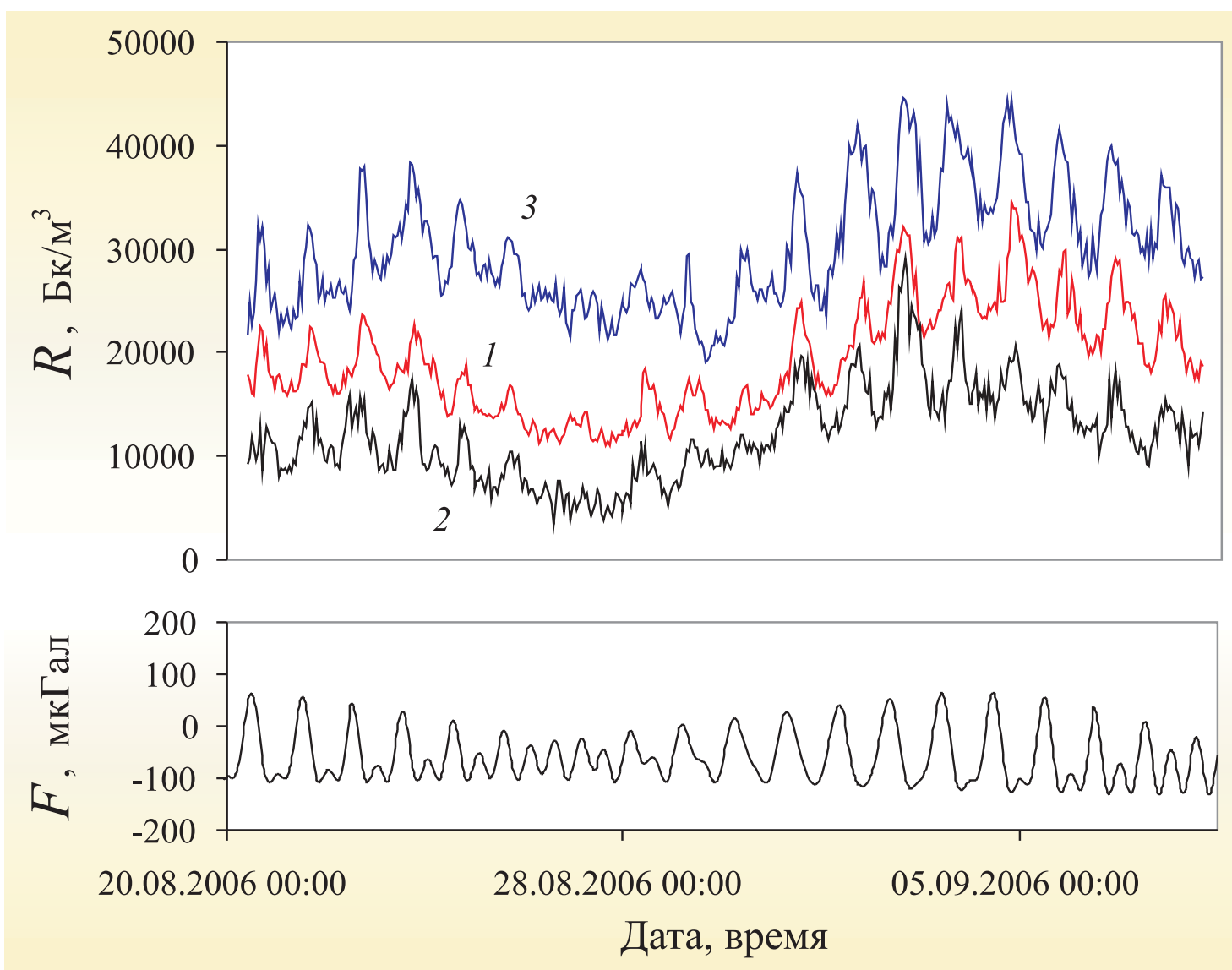

Рис. 3. Временные вариации объемной $R$ в пунктах 1-3 , расположенных на разных участках Ногинского разлома (на нижней панели приведена вариация приливной силы).

Fig. 3. Variations of volume activity of soil radon, $R$ in time on sites 1, 2 and 3 in different segments of the Noginsky fault (bottom - variations of the tidal force).

почвенного радона для некоторых участков земной коры. В частности, на рис. 2 представлены уникальные результаты, полученные в период высокой долговременной стабильности метеоусловий, когда влияние барических вариаций в атмосфере на эманационный процесс можно исключить.

Наличие ярко выраженных периодичностей во временных вариациях объемной активности радона в подпочвенной атмосфере (рис. 2, 3) позволяет установить наиболее вероятную причину изменения проницаемости среды со временем. Полученные данные свидетельствует о том, что во всех без исключения пунктах регистрации наблюдается околосуточная периодичность $R$, которая подтверждается повторными измерениями, выполненными через большой промежуток времени. При этом, околосуточные вариации объемной активности подпочвенного радона близки по характеру (как это видно из рис. 2, 3) к временным изменениям приливной силы $F$, правда, с некоторым запаздыванием $\Delta T$, величина которого для разных пунктов может составлять от 1 до 10 час.

Одновременно с околосуточной периодичностью в зонах влияния крупных тектонических структур отчетливо проявляется двухнедельная цикличность вариаций $R$, которая представлена последовательным увеличением и уменьшением амплитуды околосуточных вариаций, и так же хорошо согласуется с двухнедельными вариациями приливной силы $F$.

Повсеместное наличие околосуточных и двухнедельных вариаций $R$, а также их хорошая корреляция с вариациями приливной силы (коэффициент ранговой корреляции Спирмена с учетом сдвига на время запаздывания $\Delta T$ составляет для разных участков земной коры величину в диапазоне 0.68-0.82 при значимости 0.95) позволяют сделать заключение, что указанные периодичности временных вариаций объемной активности подпочвенного радона с высокой вероятностью связаны с приливными деформациями приповерхностного слоя земной коры. Это неудивительно, так как возможная величина приливных деформаций на каналах миграции газов в верхнем слое земной коры (в первую очередь это тектонические разломы) с учетом концентрации деформаций на тектонических нарушениях может достигать величины $10^{-7}$, а в отдельных 


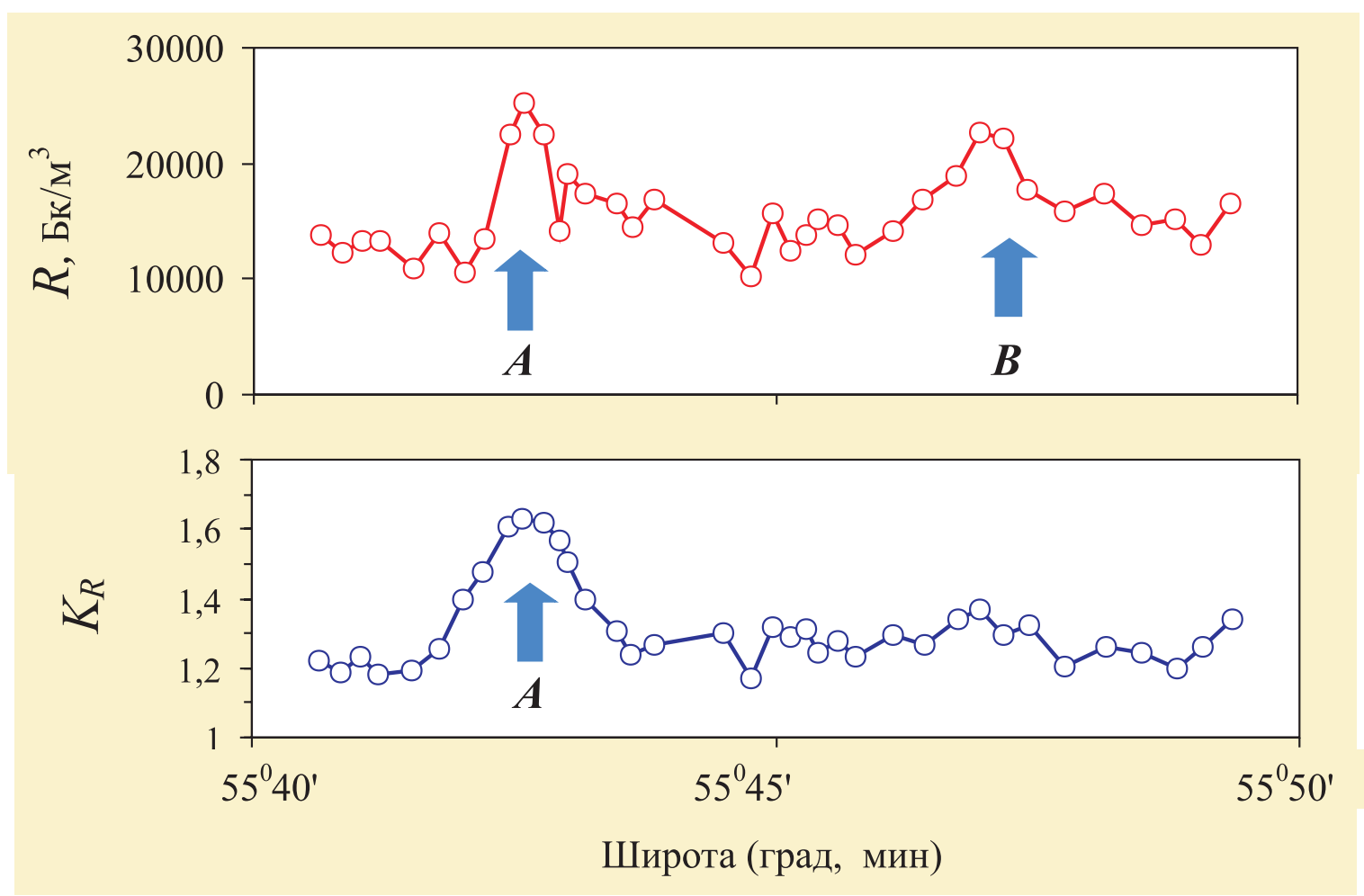

Рис. 4. Вариация объемной активности подпочвенного радона $R$ и относительный коэффициент ее приращения $K_{R}$ в приливной волне вдоль субмеридионального профиля, пересекающего Ногинский разлом.

Fig. 4. The variation of volume activity of soil radon, $R$ and its relative increment factor, $K_{R}$ in the tidal wave along the submeridional profile across the Noginsky fault.

случаях $10^{-6}$ [Adushkin, Spivak, 2007].

Данные рис. 2 и 3 свидетельствуют также о том, что не только абсолютная интенсивность эманаций, но также амплитуда временных вариаций в зонах влияния разломов существенно выше по сравнению с серединными участками структурных блоков.

Естественно предполагать, что зоны реально существующих разломов испытывают значительно большие деформации по сравнению с более консолидированными участками среды, расположенными вне зоны их влияния, вследствие чего в разломных зонах наблюдаются более интенсивные вариации радоновых эманаций. Это хорошо демонстрирует рис. 4, на котором совместно с пространственными вариациями объемной активности радона $R$ приведена величина изменения интенсивности радоновых эманаций вследствие действия приливной силы, которую допустимо характеризовать коэффициентом приращения:

$$
K_{R}=\frac{R_{\max }}{R_{\min }},
$$

где $R_{\max }$ и $R_{\min }$ - соответственно максимальное и минимальное суточные значения объемной активности подпочвенного радона, зарегистрированные в конкретном пункте за вычетом тренда, связанного с ва- риацией атмосферного давления.

Точка $A$ на рис. 4 соответствует реальному расположению серединной линии разлома, максимум вариации $R$ в точке $B$ связан с повышенной интенсивностью источника радона (в точке $B$ отсутствует необходимая реакция среды в виде ее разуплотнения в приливной волне, что является характерной особенностью структурных нарушений).

\section{3. ПРОЯВЛЕНИЕ РАЗЛОМНЫХ ЗОН В ПОЛЕ МИКРОСЕЙСМИЧЕСКИХ КОЛЕБАНИЙ}

Разрывные нарушения земной коры оказывают существенное влияние на микросейсмический фон. Это связано с повышенной деформируемостью материалазаполнителя разломных зон по сравнению с горными породами, формирующими структурные блоки. В частности, пониженная жесткость тектонических нарушений [Kocharyan, Spivak, 2003; Spivak, 2011] и, как следствие, повышенная подвижность дробленой горной породы в теле разлома определяют специфически высокую реакцию самого разлома и среды, находящейся в зоне его влияния, на слабые внешние воздействия по сравнению с серединными участками структурных блоков. Результаты инструментальных наблю- 
дений свидетельствуют, например, о том, что слабое возмущение земной коры в виде приливных деформаций вызывает повышенные вариации амплитуды отдельных (характерных для конкретного участка земной коры) спектральных составляющих микросейсмических колебаний, а также интенсивность релаксационных процессов как на самих разломах, так и на участках, расположенных в их окрестностях [Adushkin, Spivak, 2006; Spivak, Kishkina, 2004].

В качестве примера на рис. 5 приведены совместно вариации приливной силы $F$ и среднеквадратической амплитуды микросейсмического фона $A$ в диапазоне частот 7-10 Гц для пунктов, расположенных в разломной зоне и на серединном участке структурного блока. Данные свидетельствуют о том, что, во-первых, амплитудные вариации высокочастотной составляющей микросейсмического фона существенно выше в разломной зоне, а во-вторых, о достаточно высокой корреляции величин $A$ и $F$ (коэффициент линейной корреляции $K$ составляет 0.71) при некотором опережении реакции микросейсмического фона на внешнее силовое воздействие (максимум амплитуды микросейсмического фона совпадает с максимумом производной $F^{\prime}$ ).

Влияние разломных зон на дискретную составляющую сейсмического фона. Существенное влияние оказывают разрывные нарушения на дискретную составляющую высокочастотного микросейсмического фона, представленную импульсами релаксационного типа (ИРТ), координаты очагов которых с достаточной для практических оценок точностью определяются сейсмическими методами [Spivak, Kishkina, 2004].

Анализ пространственного распределения очагов ИРТ свидетельствует об их высокой локализации в разломных зонах и, особенно, в зонах их сочленения. При этом разломные зоны маркируются наиболее крупными событиями. В качестве примера на рис. 6 приведены результаты сейсмических наблюдений, выполненных с помощью оперативных малоапертурных сейсмических групп на южной окраине Московской синеклизы [Adushkin et al., 2006]. Из представленных данных, в частности, следует, что очаги ИРТ с энергией, превышающей 10 Дж, группируются в разломных зонах как первого, так и более высокого порядка.

Представляется вполне правдоподобным, что локализация очагов более крупных по энергии ИРТ происходит в зонах динамического влияния активных разломов. Это подтверждается как результатами линеаментного анализа, так и прямыми исследованиями с использованием геологических методов [Ivanchenko, 2012]. Можно считать, что интенсивность релаксационных процессов (количество микросейсмических импульсов, их амплитудные и энергетические характеристики) отражает степень современной активности разломов.

Интересно отметить, что именно в разломных зонах (аналогично на участках земной коры, характеризую- щихся высокой тектонической нарушенностью) наблюдается корреляция между амплитудными вариациями микросейсмического фона определенного диапазона частот и интенсивностью релаксационных процессов (количеством $N$ актов релаксации в единицу времени). В качестве примера на рис. 7 приведены результаты сейсмической регистрации, выполненной в зоне активной Курайской тектонической структуры (Горный Алтай). Коэффициент корреляции между временными вариациями среднеквадратической амплитуды микросейсмических колебаний и количеством актов релаксации составляет 0.75 при значимости $r=0.995$.

\section{4. ПРЕОБРАЗОВАНИЕ ЭНЕРГИИ МЕЖДУ ГЕОФИЗИЧЕСКИМИ ПОЛЯМИ РАЗНОЙ ПРИРОДЫ}

Тектонические нарушения выполняют роль активного посредника в процессах преобразования энергии между геофизическими полями разной природы. Например, интенсивные эманации радиоактивного радона, наблюдаемые в разломных зонах, оказывают сильное влияние на проводимость приземного слоя атмосферы, что, в свою очередь, приводит к вариациям электрического поля ${ }^{3}$. В качестве примера на рис. 8 приведены совместно усредненные за трое суток временные вариации объемной активности подпочвенного радона $\Delta R$ и вертикальной компоненты электрического поля в приземном слое атмосферы $\Delta E_{z}$ (регистрация в условиях «хорошей погоды»).

Из сравнения графиков, представленных на рис. 8, видно, что увеличение объемной активности подпочвенного радона вызывает уменьшение электрического поля и наоборот, что позволяет предполагать наличие обратной зависимости между рассматриваемыми величинами $R$ и $E_{z}$. Сравнение графиков свидетельствует о достаточно высокой корреляции между радоновыми эманациями по разломной зоне и напряженностью электрического поля в приземном слое атмосферы (коэффициент ранговой корреляции Спирмена приближается к 0.9 при статистической значимости не менее 0.95).

Аналогичную зависимость между $R$ и $E_{z}$ демонстрируют результаты синхронных измерений, выполненных вдоль профилей, пересекающих Курайский разлом (рис. 9). Как это видно из данных рис. 9, пространственные вариации $E_{z}$ и $R$ находятся в противофазе. Здесь необходимо отметить пространственную немонотонность изменений величин $E_{z}$ и $R$, что можно объяснить сложным внутренним строением рассматриваемой тектонической структуры (разлом шириной

\footnotetext{
3 Эффект редко наблюдается на серединных участках структурных блоков вследствие существенно более низких значений и вариаций объемной активности подпочвенного радона по сравнению с разломными зонами.
} 

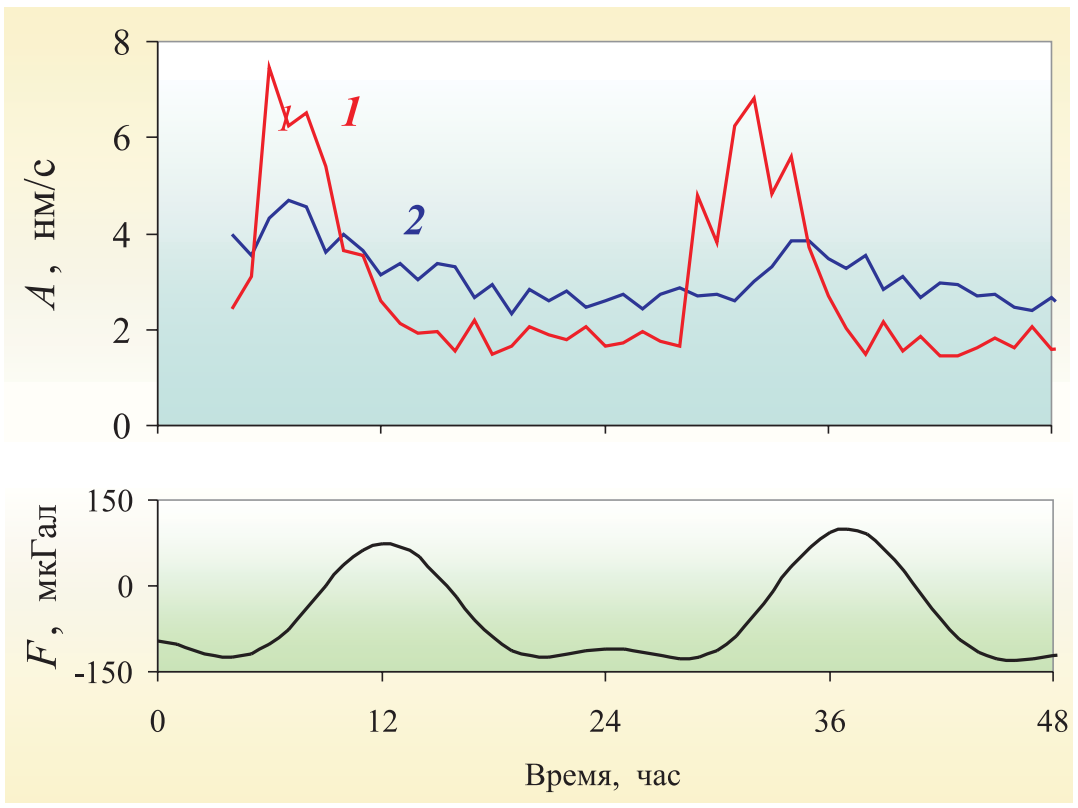

Рис. 5. Вариации среднеквадратической амплитуды микросейсмического фона в диапазоне частот 7-10 Гц в пунктах, расположенных на разломе II порядка относительно Нелидово-Рязанской шовной зоны (кривая 1 на верхней панели) и вне зоны его влияния (кривая 2 на верхней панели); нижняя панель - вертикальная составляющая приливной силы.

Fig. 5. Variations of the root-mean-square amplitude of the microseismic background in the frequency range from 7 to 10 hz on sites located at the fault of the 2nd order in relation to the Nelidovo-Ryazan suture zone (curve 1 in the top panel) and outside the zone of its impact (curve 2 in the top panel). Bottom - vertical component of the tidal force.

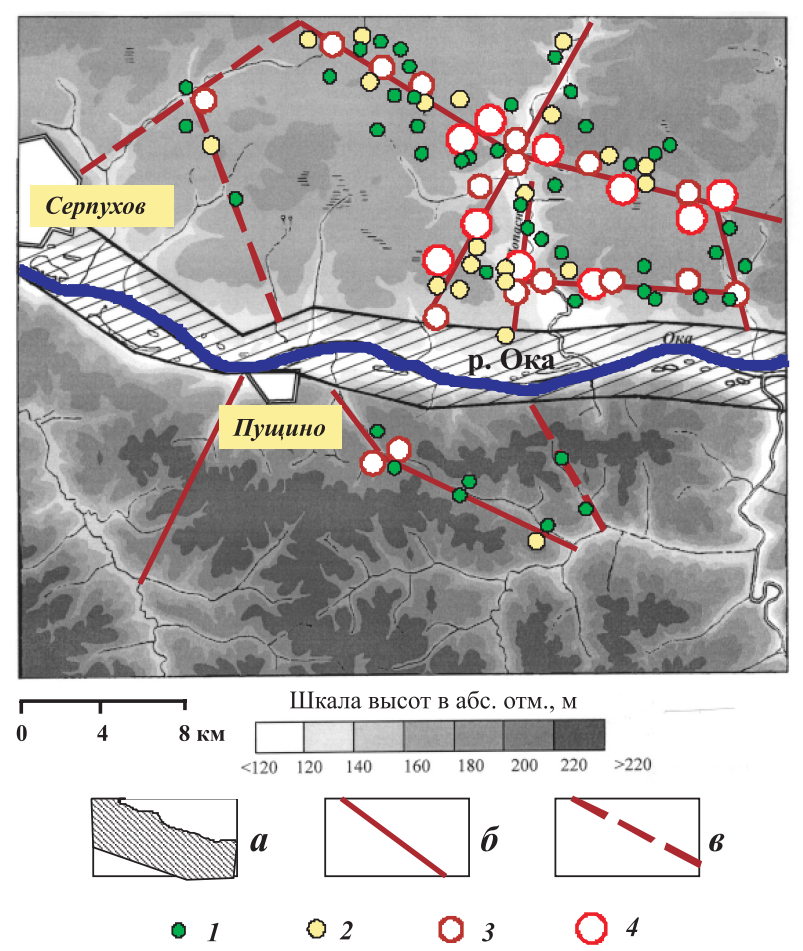

Рис. 6. Тектоническое строение и локализация очагов ИРТ, зарегистрированных в течение трех суток на Приокском участке Нелидово-Рязанской тектонической структуры $(a)$; б и в - оперяющие тектонические нарушения соответственно II и III порядка; энергия ИРТ, Дж: 1 - менее 10; 2 - 10-20; 3 - 20-40; 4 - свыше 40.

Fig. 6. The tectonic structure and locations of relaxation impulse foci registered within three days in the Prioksky segment of the Nelidovo-Ryazan suture zone $(a)$; $\sigma$ and 8 - feathering tectonic faults of the $2^{\text {nd }}$ and $3^{\text {rd }}$ orders, respectively; relaxation impulse energy, joule: 1 - below $10 ; 2-10$ to $20 ; 3-20$ to $40 ; 4$ - above 40 . 

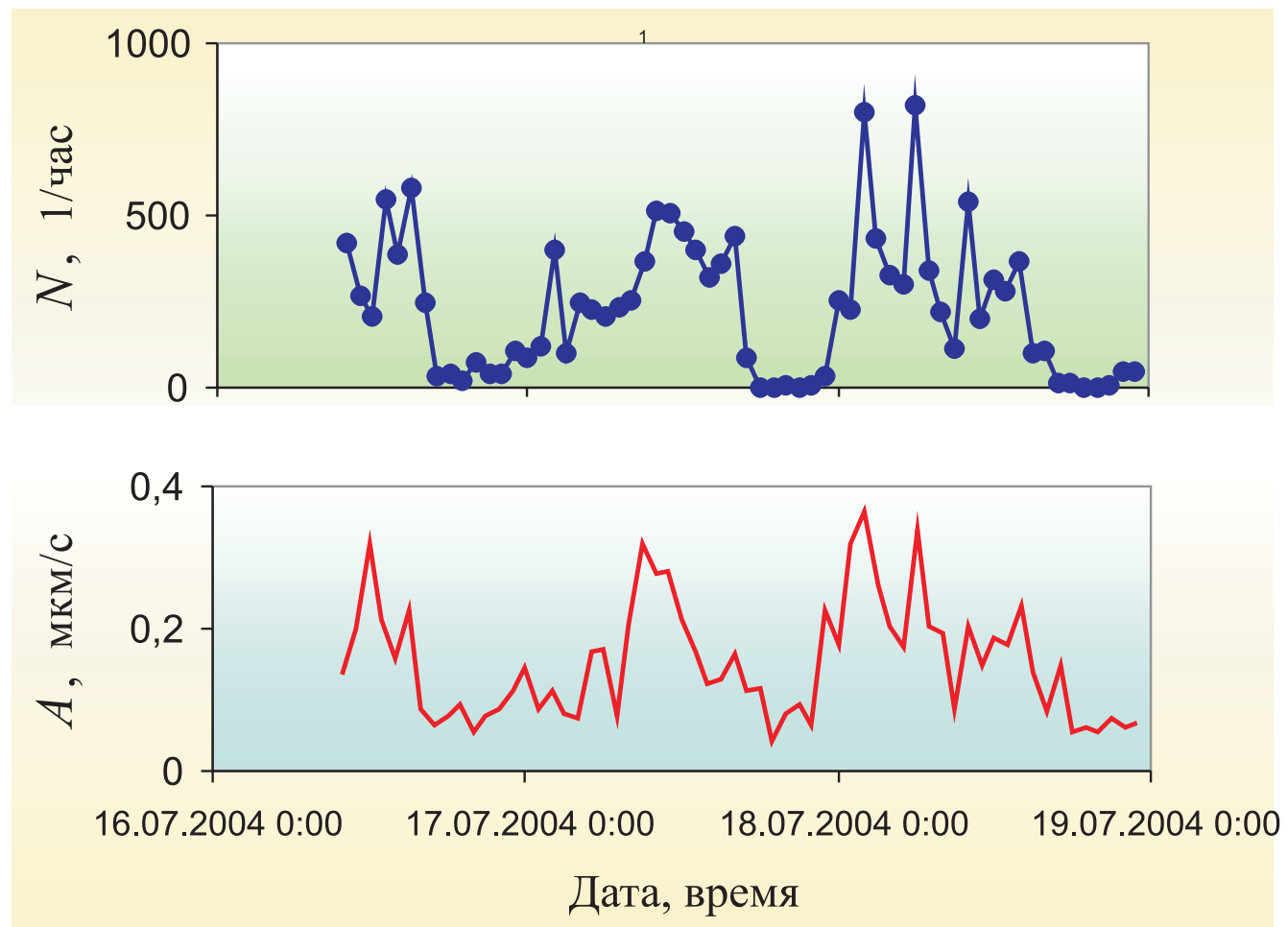

Рис. 7. Количество актов релаксации (верхняя панель) и сезонные вариации среднеквадратичной амплитуды сейсмического фона (нижняя панель) в зоне влияния Нелидово-Рязанской шовной зоны.

Fig. 7. The number of relaxation acts (top) and seasonal variations of the root-mean-square amplitude of the seismic background (bottom) in the zone influenced by the Nelidovo-Ryazan suture zone.

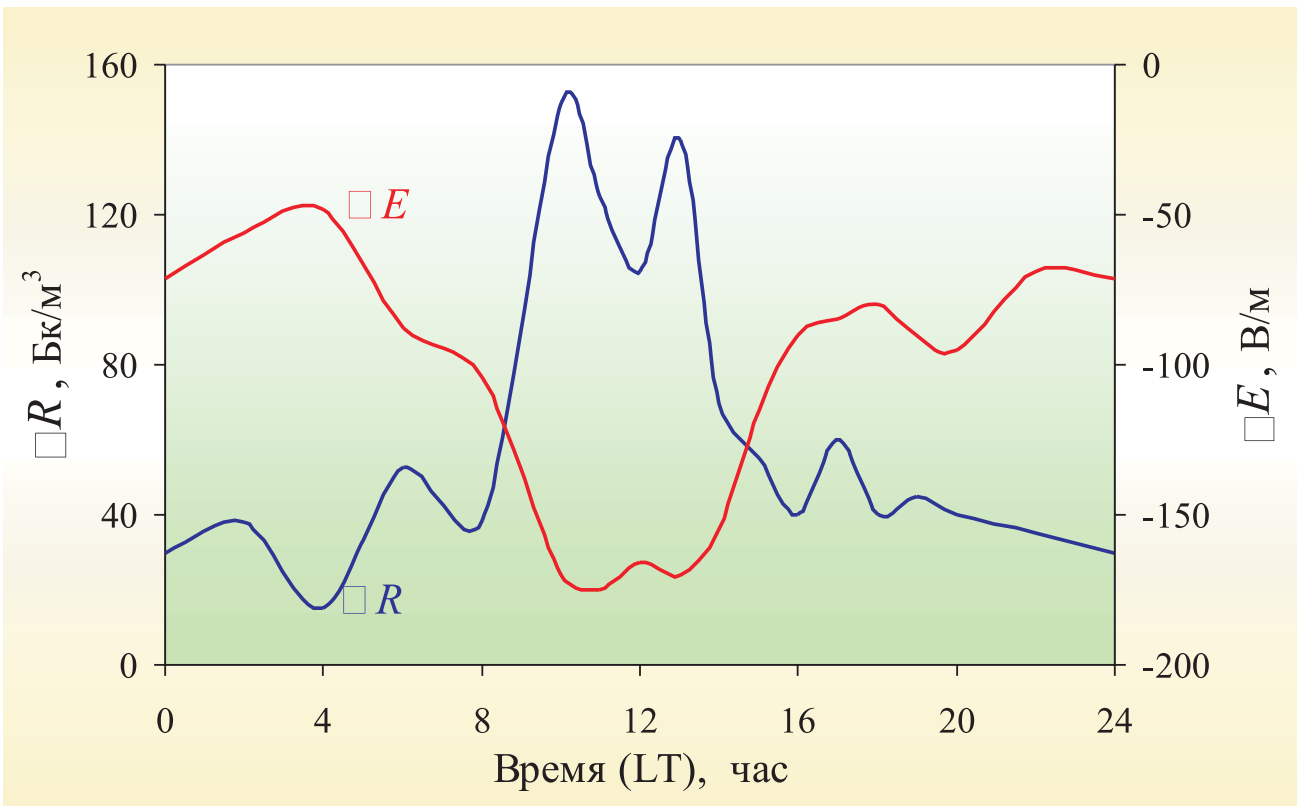

Рис. 8. Относительные вариации объемной активности подпочвенного радона $\Delta R$ и вертикальной компоненты электрического поля в приземном слое атмосферы $\Delta E$ в зоне влияния глубинного разлома.

Fig. 8. Relative variations of volume activity of soil radon, $\Delta R$ and the vertical component of the electric field in the near-soil atmospheric layer, $\Delta E$ in the zone influenced by the deep fault. 


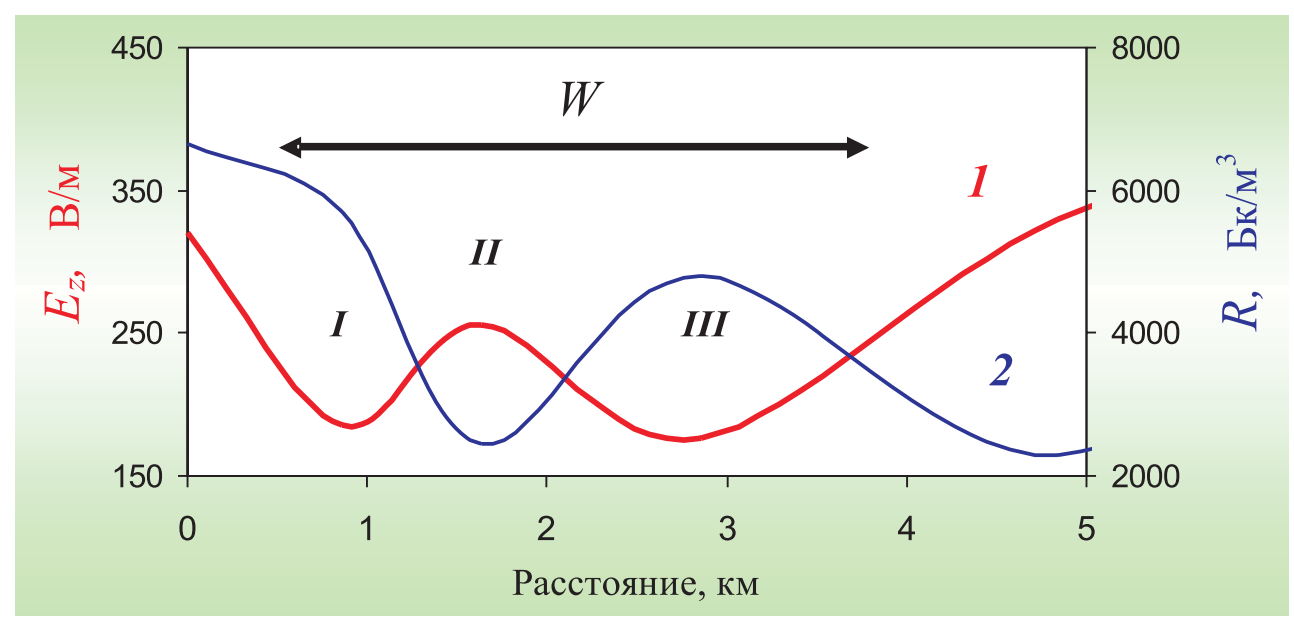

Рис. 9. Результаты синхронной регистрации вертикальной компоненты напряженности электрического поля в приземном слое атмосферы $E_{z}(1)$ и объемной активности подпочвенного радона (2) вдоль профиля, пересекающего Курайскую разломную зону шириной $W$ (Горный Алтай).

Немонотонность пространственного изменения $E_{z}$ и $R$ можно объяснить сложным строением зоны, представленной чередованием более рыхлых (I и III) и более плотных (II) зон.

Fig. 9. Results of synchronous registration of the vertical component of intensity of the electric field in the near-soil atmospheric layer, $E_{z}(1)$ and volume activity of soil radon, $R(2)$ along the profile across the Kurai fault zone in Gorny Altai (W - width of the zone).

Non-monotone spatial variations of $E_{z}$ and $R$ may be due to the structure of the zone containing sub-zones composed of loose (I and $\left.I I I\right)$ and dense (II) rocks.

W представлен чередованием менее и более плотных 30н).

Значительное увеличение объема эманаций радиоактивного радона ${ }^{222} \mathrm{Rn}$ в разломных зонах может в отдельных случаях привести не только к падению абсолютной величины электрического поля в приземном слое атмосферы, но даже изменению его знака. В качестве примера на рис. 10 представлены результаты синхронных измерений объемной активности подпочвенного радона $R$ и вертикальной компоненты электрического поля в приземном слое атмосферы $E_{z}$ в Курайской разломной зоне в период ее высокой активизации, сопровождающейся интенсивным увеличением радоновых эманаций. Данные рис. 10 демонстрируют изменение знака электрического поля с положительного на отрицательный при достижении объемной активностью подпочвенного радона значений, превышающих 8500 Бк/м³ (вертикальная компонента электрического поля на серединных участках структурных блоков варьируется в рассматриваемый период времени в диапазоне 150-220 B/м).

Связь между $R$ и $E_{z}$ демонстрируют также данные, полученные при инструментальных наблюдениях в Тункинской долине (Байкальская рифтовая зона). В частности, на рис. 11 представлены результаты инструментальных наблюдений, выполненных вдоль одного из субмеридиональных профилей, пересекающих
Тункинскую рифтовую зону. Приведенные на рис. 11 результаты измерений показывают обратную зависимость между объемной активностью подпочвенного радона и величиной электрического поля в приземном слое атмосферы (пространственные вариации $E_{z}$ и $R$ находятся в противофазе: поступление радиоактивного радона вызывает уменьшение напряженности вертикальной составляющей электрического поля).

Необходимо отметить, что резкое повышение объемной активности подпочвенного радона на северной окраине Тункинского рифта определяется наличием здесь Тункинского разлома.

Преобразование механической энергии сейсмических колебаний в энергию электромагнитного поля. Повышенная раздробленность вещества и, как следствие, имеющиеся возможности для дифференциальных движений отдельностей определяют специфические трибоэффекты в пределах разломной зоны при ее деформировании, например во время прохождения сейсмической волны. В качестве примера на рис. 12 приведены результаты синхронной регистрации сейсмических колебаний (массовый взрыв на Щуровском карьере в 64 км от места регистрации), электрического и магнитного полей в зоне влияния тектонического нарушения II порядка относительно Нелидово-Рязанской тектонической структуры. Данные рис. 12 демонстрируют, что в период прохождения группы поперечных 


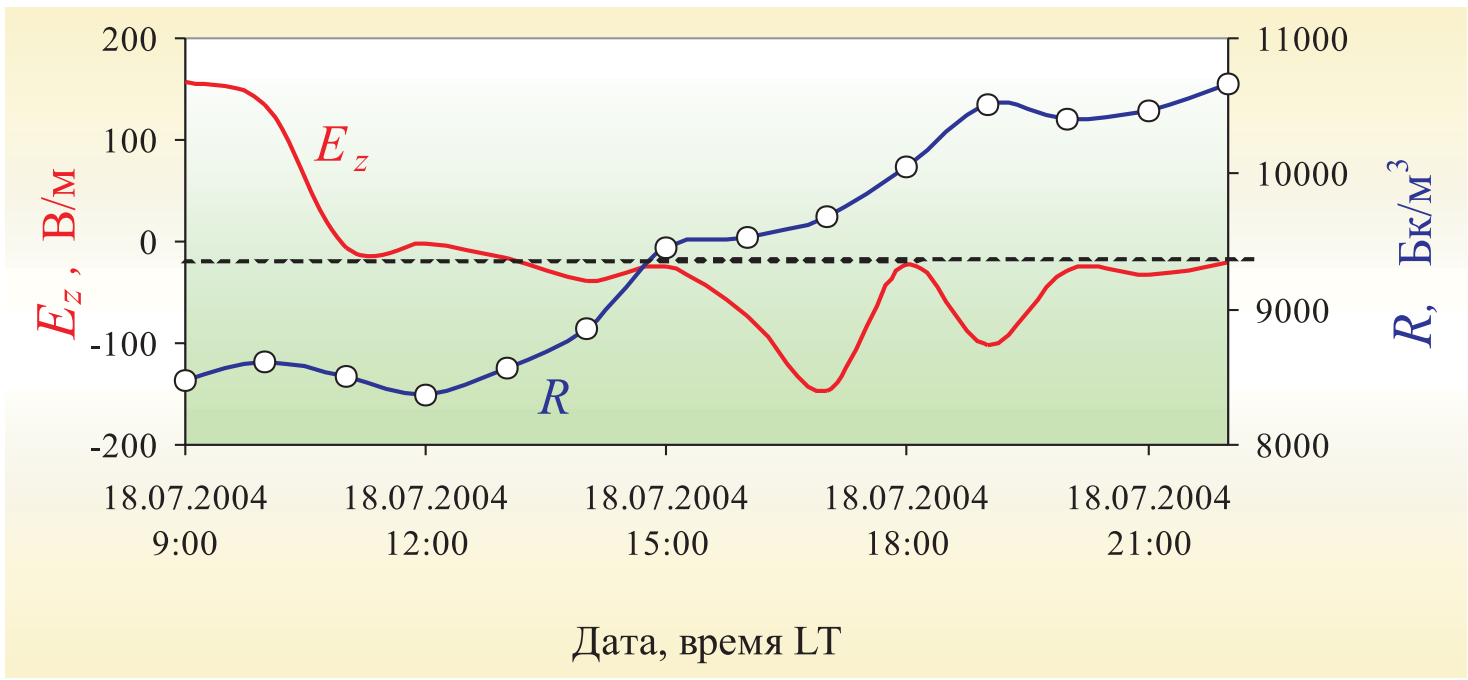

Рис. 10. Временные вариации объемной активности подпочвенного радона $R$ и вертикальной составляющей электрического поля $E_{z}$ в приземном слое атмосферы в зоне Курайской тектонической структуры.

Fig. 10. Variations of volume activity of soil radon, $R$ and the vertical component of intensity of the electric field, $E_{z}$ in time in the near-soil atmospheric layer in the zone influenced by the Kurai fault.

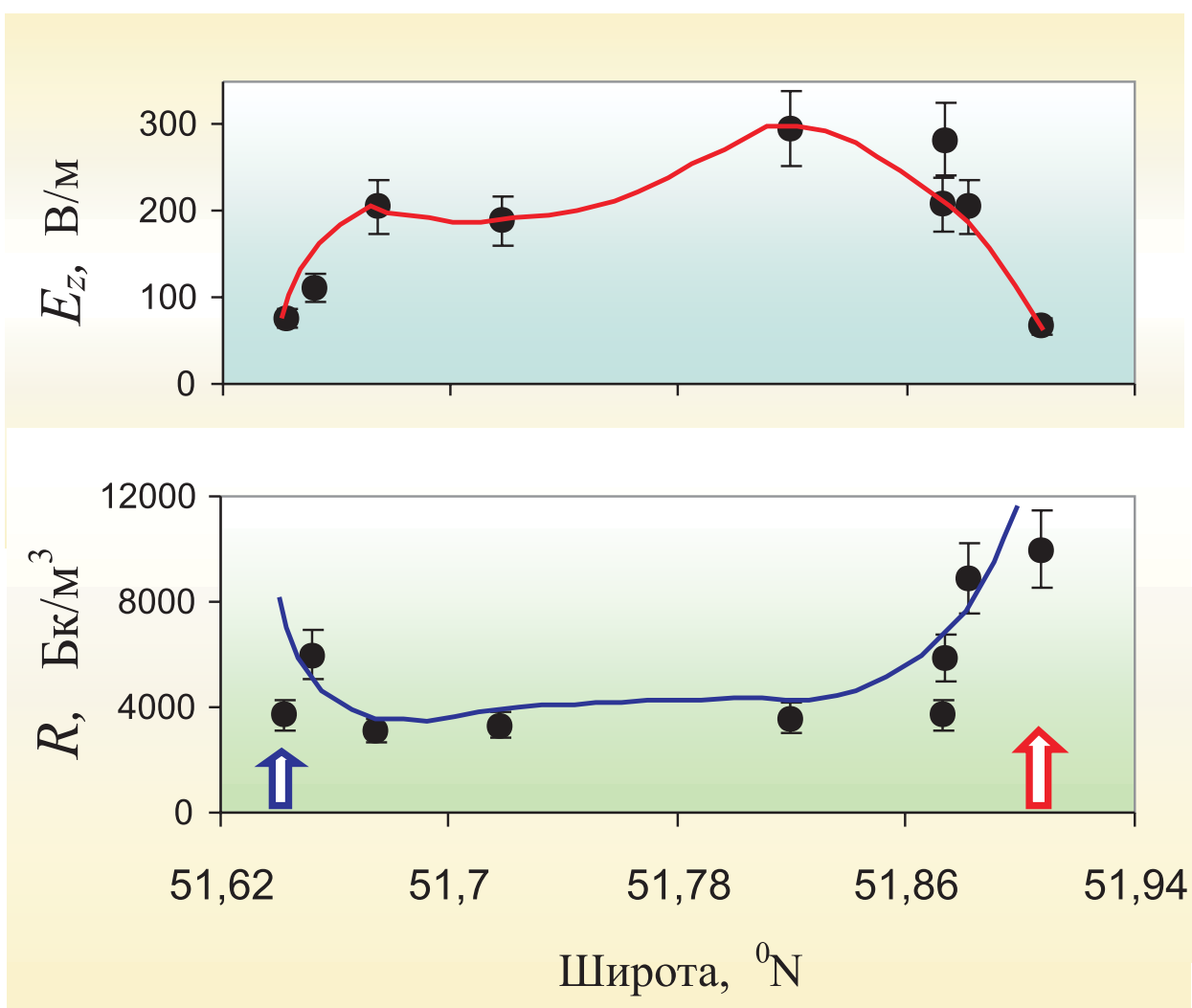

Рис. 11. Результаты синхронной регистрации вертикальной компоненты электрического поля в приземном слое атмосферы $E_{z}$ и объемной активности подпочвенного радона $R$ вдоль профиля, пересекающего Тункинскую долину в направлении ЮC (вертикальными стрелками обозначены разломы, окаймляющие Тункинский рифт; красная стрелка обозначает положение Тункинского разлома).

Fig. 11. Results of synchronous registration of the vertical component of intensity of the electric field in the near-soil atmospheric layer, $E_{z}$ and volume activity of soil radon, $R(2)$ along the profile across the Tunka valley (south to north) (vertical arrows - faults bordering the Tunka rift; red arrow - position of the Tunka fault). 

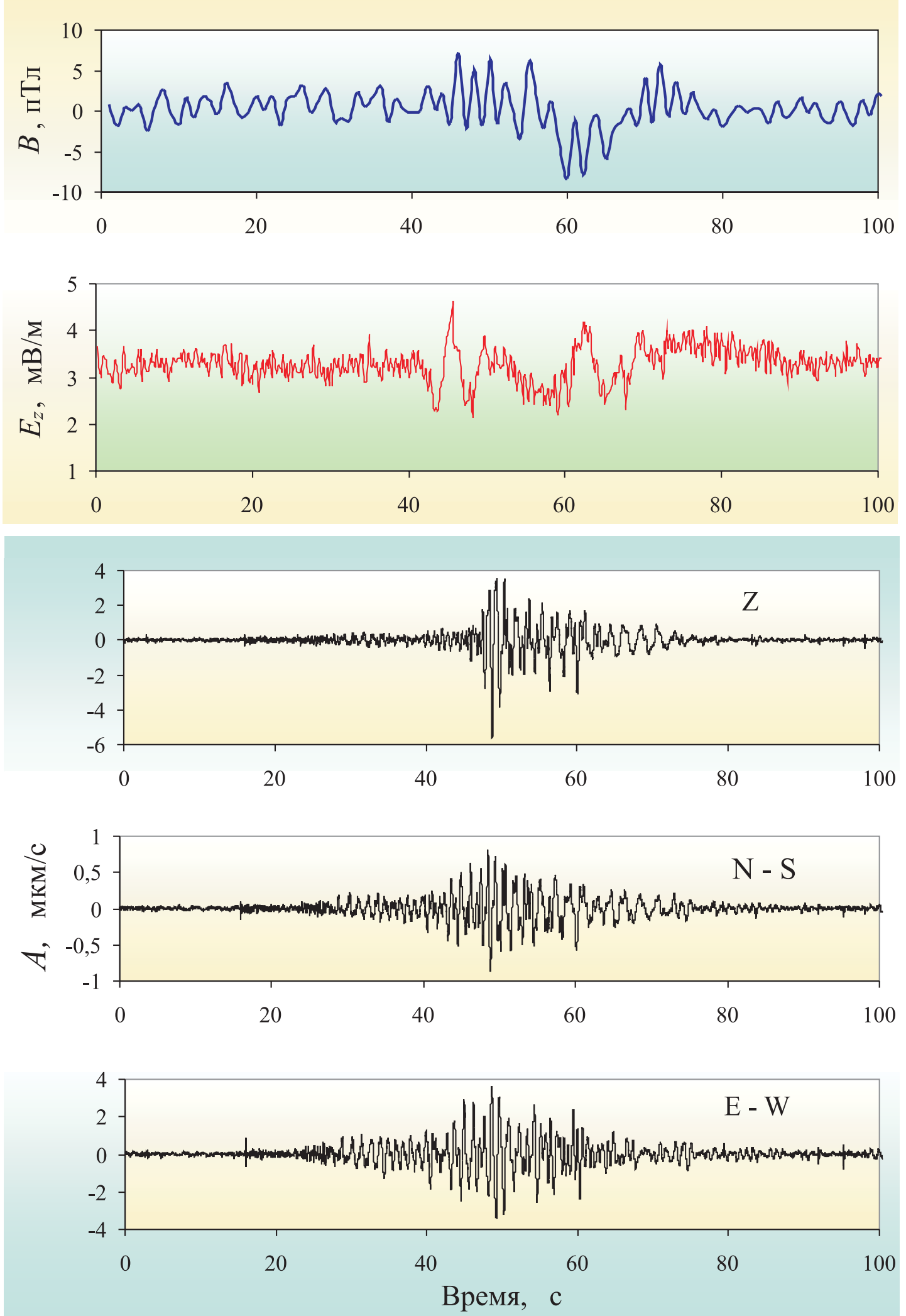

Рис. 12. Результаты синхронной регистрации вариаций вертикальной компоненты электрического поля $E_{z}$ и геомагнитных вариаций (вариаций магнитной индукции $B$ ) при распространении сейсмических волн, вызванных массовым взрывом на Щуровском карьере (амплитуда сейсмического сигнала $A$ представлена в виде трех компонент: вертикальной $Z$, север - юг $(N-S)$ и восток - запад $(E-W)$ на трех нижних панелях).

Fig. 12. Results of synchronous registration of variations of the vertical component of intensity of the electric field, $E_{z}$ and magnetic induction variations, $B$ due to propagation of seismic waves from the major blast in the Shchurovsky quarry (three bottom panels three components of seismic signal amplitude, $A$ : $Z$ - vertical, $N-S$ - north - south, and $E-W$ - east - west). 

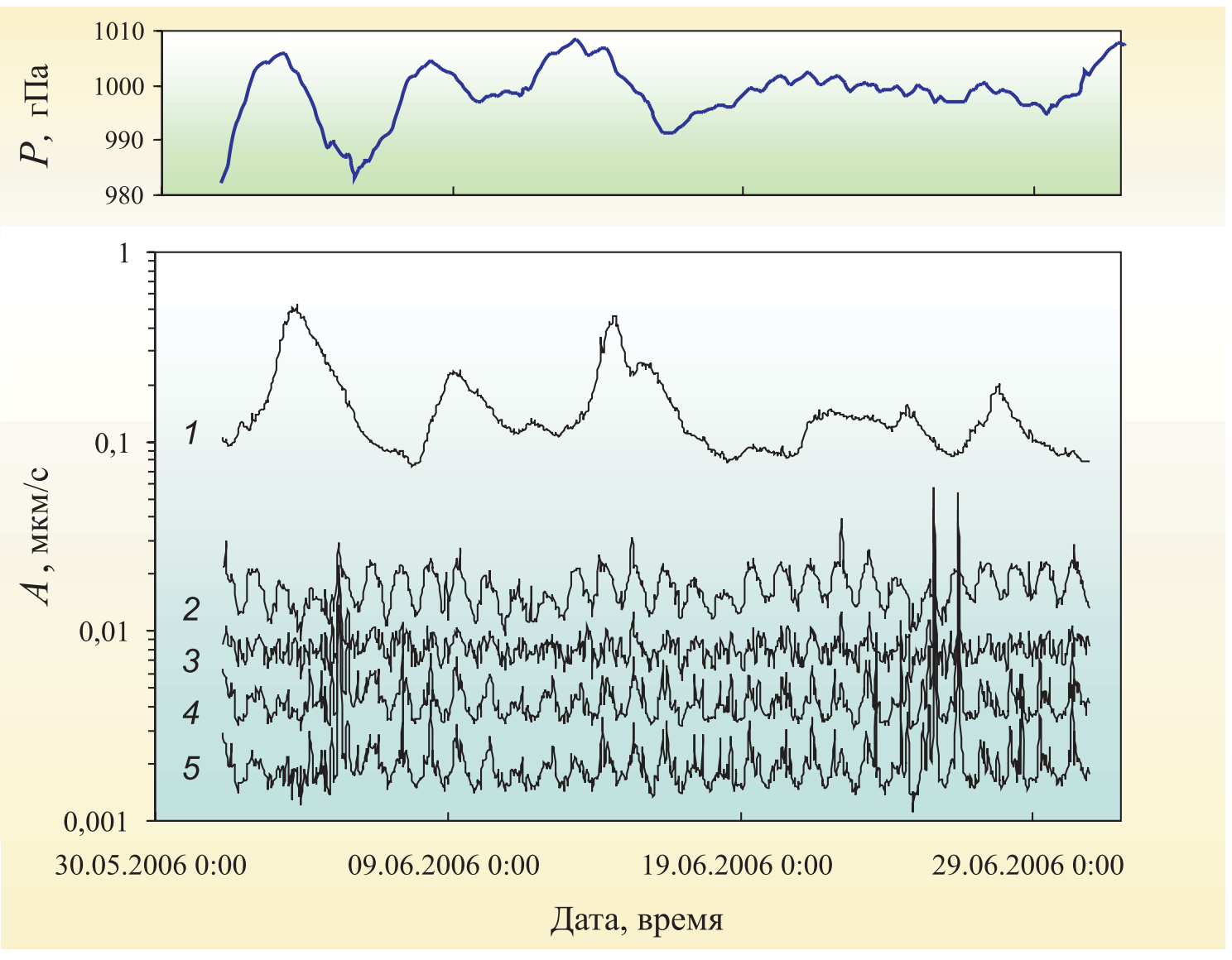

Рис. 13. Вариации амплитуды сейсмического фона в разных диапазонах частот (нижняя панель) в период интенсивных вариаций атмосферного давления (верхняя панель).

Диапазон частот, Гц: $1-0.1-1 ; 2-1-2 ; 3-2-4 ; 4-4-6 ; 5-6-8$.

Fig. 13. Variations of seismic background amplitudes in various frequency ranges (bottom) in the period of intensive atmospheric pressure variations (top).

Frequency range (hertz): $1-0.1$ to $1 ; 2-1$ to $2 ; 3-2$ to $4 ; 4-4$ to $6 ; 5-6$ to 8 .

волн наблюдаются ярко выраженные вариации индукции магнитного поля и вертикальной компоненты электрического поля в приземном слое атмосферы. Указанный эффект устойчиво регистрируется при амплитудах сейсмического сигнала свыше 5-10 мкм/с вне зависимости от источника (карьерные взрывы, крупные ИРТ). По мере снижения амплитуды сейсмического сигнала вероятность возникновения амплитудных вариаций электромагнитного поля существенно уменьшается и определяется свойствами конкретного участка разлома.

Характерной особенностью электрического поля в грунте (горизонтальная компонента) является наличие импульсных колебаний на участках земной коры, прилегающих к зонам тектонических разломов. При этом количество и амплитуды регистрируемых импульсов зависят от современной активности тектонической структуры. Для примера: если в зоне активной на современном этапе Курайской тектонической структуры
(Горный Алтай) регистрируется до 200 импульсов в час, то в зоне Нелидово-Рязанской тектонической структуры, расположенной в районе слабой тектонической активности, таких импульсов регистрируется не более 10 в час [Adushkin et al., 2006].

Инструментальные наблюдения, выполненные в разных регионах, свидетельствуют о наличии в земной коре большого количества электрических и микросейсмических сигналов импульсного типа, которые в подавляющем большинстве случаев локализуются в зонах влияния разломов. В значительном количестве случаев электрические и сейсмические импульсы сопутствуют друг другу (рис. 13), причем электрические импульсы опережают по времени вступление микросейсмических импульсов. Отмечается сходство статистических показателей [Soloviev, Spivak, 2009] и хорошее совпадение азимутов распространения электрических и микросейсмических сигналов в этой группе. Существенно также то, что расстояния до источника, 
определяемые, с одной стороны, по результатам измерений с помощью сейсмической группы, а с другой по времени запаздывания сейсмического сигнала относительно электрического $t_{d}$, близки между собой. Все это позволяет предполагать, что с большой вероятностью сейсмические и электрические сигналы генерируются одним источником.

Как показано ранее [Loseva et al., 2012; Soloviev, Spivak, 2009], в качестве одного из возможных механизмов синхронной генерации микросейсмических и электрических импульсов в слабообводненной среде допустимо рассматривать скачкообразную деформацию активных структурных блоков земной коры в стесненных условиях в процессе их разгрузки (релаксации). В этом случае амплитуда дифференциальной подвижки активного блока напрямую определяет амплитуду сейсмического сигнала. Параметры же электрического сигнала определяются механизмом разделения электрических зарядов либо изменением токовых систем при деформировании активного блока или материала-заполнителя межблоковых промежутков в процессе релаксации блока (наиболее вероятным представляется механизм, связанный с электрической поляризацией необводненных горных пород при резком изменении напряженно-деформированного состояния [Soloviev, Spivak, 2009]).

Здесь следует отметить, что наиболее благоприятные условия для разгрузки структурных блоков существуют в зоне влияния разлома. Это определяет повышенную интенсивность релаксационных процессов в разломной зоне и, как следствие, выраженную локализацию в ней источников микросейсмических и электрических сигналов.

\section{5. ОТКЛИК НА СЛАБЫЕ ВОЗМУЩЕНИЯ СРЕДЫ}

Выше отмечалось, что отличительные особенности механических свойств дробленых горных пород, заполняющих тело разлома, определяют его повышенную реакцию на слабые внешние воздействия. Данные инструментальных наблюдений свидетельствуют о том, что, помимо рассмотренных модуляций объемной активности подпочвенного радона и отдельных спектральных составляющих микросейсмических колебаний твердым приливом, в разломных зонах и на участках земной коры, характеризующихся высокой тектонической нарушенностью (наличие достаточно плотной сети разломов), наблюдаются эффекты, связанные с реакцией микросейсмического и эманационного полей на барические возмущения атмосферы в месте проведения инструментальных наблюдений. При этом эффект от воздействия барических возмущений атмосферы значительно сильнее в разломных зонах.

На основе анализа отклика земной коры на барические воздействия можно оценивать степень нарушенности ее конкретных участков, картировать разломные зоны, выявлять неоднородности строения, а также организовывать контроль за изменениями свойств твердой среды в результате воздействий природного и техногенного происхождения.

Атмосфера, как газовая оболочка Земли, характеризуется значительными пространственными и временными вариациями давления. В качестве источников барических вариаций в атмосфере выступают как глобальные, так и локальные явления и процессы. Естественно, что разные источники вызывают барические возмущения разной интенсивности и в разных диапазонах частот. Для сравнительного анализа представляет интерес рассмотрение основных, наиболее мощных по проявлению характерных периодичностей изменения атмосферного давления. Это крупномасштабные барические возмущения атмосферы, связанные циклоническими явлениями и распространением атмосферных фронтов.

Совместный анализ результатов сейсмической регистрации и барических вариаций разной периодичности показывает, что вариации атмосферного давления вызывают заметные изменения характеристик микросейсмических колебаний как в длиннопериодной, так, что весьма важно, и в высокочастотной области. При этом нужно отметить, что вариации атмосферного давления вызывают не только изменения характеристик микросейсмического фона, но также характеристик импульсных микросейсмических сигналов релаксационного типа.

Реакция микросейсмического поля на циклонические процессы. Анализ микросейсмического шума показывает, что вариации атмосферного давления, вызванные циклонами и антициклонами, оказывают влияние в основном на длиннопериодную составляющую фоновых колебаний. В качестве примера на рис. 13 приведены совместно вариации атмосферного давления и временные вариации среднеквадратической амплитуды микросейсмического фона в разных частотных диапазонах в период, характеризующийся интенсивными циклоническими явлениями (использованы данные сейсмостанции $\mathrm{MHV}\left(54.96^{\circ} \mathrm{N}, 37.77^{\circ} \mathrm{E}\right)$, расположенной в зоне влияния Нелидово-Рязанской тектонической структуры и оперяющих разломов II порядка [Adushkin et al., 2006]).

Не останавливаясь на анализе механизма влияния атмосферного давления на геодинамические процессы в земной коре, отметим, что данные рис. 15 демонстрируют значимую корреляцию между циклоническими вариациями атмосферного давления и амплитудой фоновых микроколебаний в диапазоне частот 0.03-1.00 Гц $(K=0.65$ при значимости 0.95). Характерно то, что на частотах, превышающих 1 Гц, реакция микросейсмического фона на вариации атмосферного давления, вызванные циклонической деятельностью, не наблюдается. Также не наблюдается корреляции между вариациями атмосферного давления и интенсивностью релаксационных процессов. 


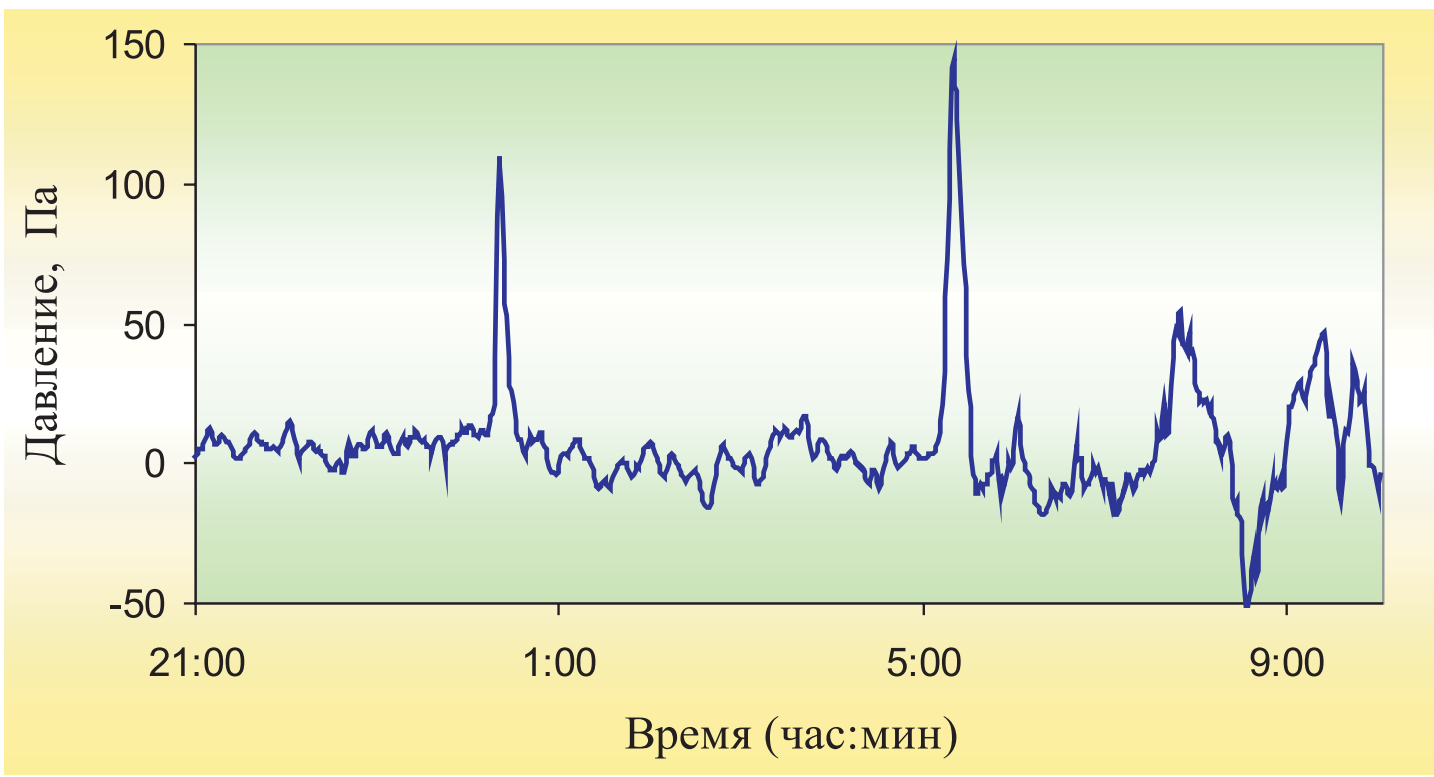

Рис. 14. Пример микробарических вариаций в атмосфере в период прохождения атмосферных фронтов 04-05 июня 2006 г. на сейсмической станции MHV.

Fig. 14. Micro-baric variations in the atmosphere during frontal passages on June 04 and 05, 2006 according to observations at the MHV seismic station.

Реакция на микробарические вариации. Микробарические вариации в приземной атмосфере связаны в основном с перемещением атмосферных (как правило, холодных) фронтов. Согласно наблюдениям, представленным в настоящей работе, их длительность составляет от 8 до 35 мин, а амплитуда вариаций давления находится в интервале 30-200 Па (рис. 14).

Результаты наблюдений, выполненных в зонах влияния разломов, свидетельствуют о существенном влиянии слабых и достаточно кратковременных вариаций атмосферного давления, вызванных прохождением атмосферных фронтов, на амплитудные и спектральные характеристики микросейсмических колебаний. В качестве примера на рис. 15 приведены вариации амплитуды, а на рис. 16 - вариации спектров микросейсмического фона в период прохождения холодного атмосферного фронта в зоне Нелидово-Рязанской тектонической структуры.

Представленные на рис. 15 и 16 данные свидетельствуют о повышении амплитуды микросейсмического фона в период распространения атмосферного фронта. При этом максимальный отклик микросейсмического поля на микробарические вариации наблюдается в диапазоне частот 4-8 Гц.

Изменение интенсивности релаксационных процессов в земной коре при микробарических вариациях в атмосфере. Анализ результатов синхронных наблюдений за барическими вариациями в атмосфере и сейсмическим фоном показывает, что более слабые по амплитуде и значительно менее длительные по срав- нению с циклонами микробарические вариации вызывают значительное увеличение интенсивности релаксационных процессов в земной коре, что проявляется, в первую очередь, в увеличении количества актов релаксации (количества ИРТ) сразу после прохождения атмосферных фронтов. В качестве примера на рис. 17 приведены совместно вариации атмосферного давления и количество ИРТ. Стрелками отмечены времена прохождения атмосферных фронтов через разломную зону. Из данных, представленных на рис. 17, хорошо видно, что именно в период прохождения атмосферного фронта наблюдается существенное увеличение интенсивности релаксационных процессов. В этом смысле показательным является период, обозначенный на рис. 17 незалитой стрелкой, когда отсутствуют длиннопериодные барические вариации.

\section{6. Выводы}

Результаты исследований свидетельствуют о существенной роли разломных зон в формировании пространственных и временных вариаций геофизических полей. Зоны влияния крупных разломов характеризуются повышенной интенсивностью релаксационных процессов, а также эманацией подземных газов. В разломных зонах и на участках земной коры с повышенной тектонической нарушенностью наблюдается более сильное влияние слабых воздействий в виде приливной деформации и барических вариаций в атмосфере 


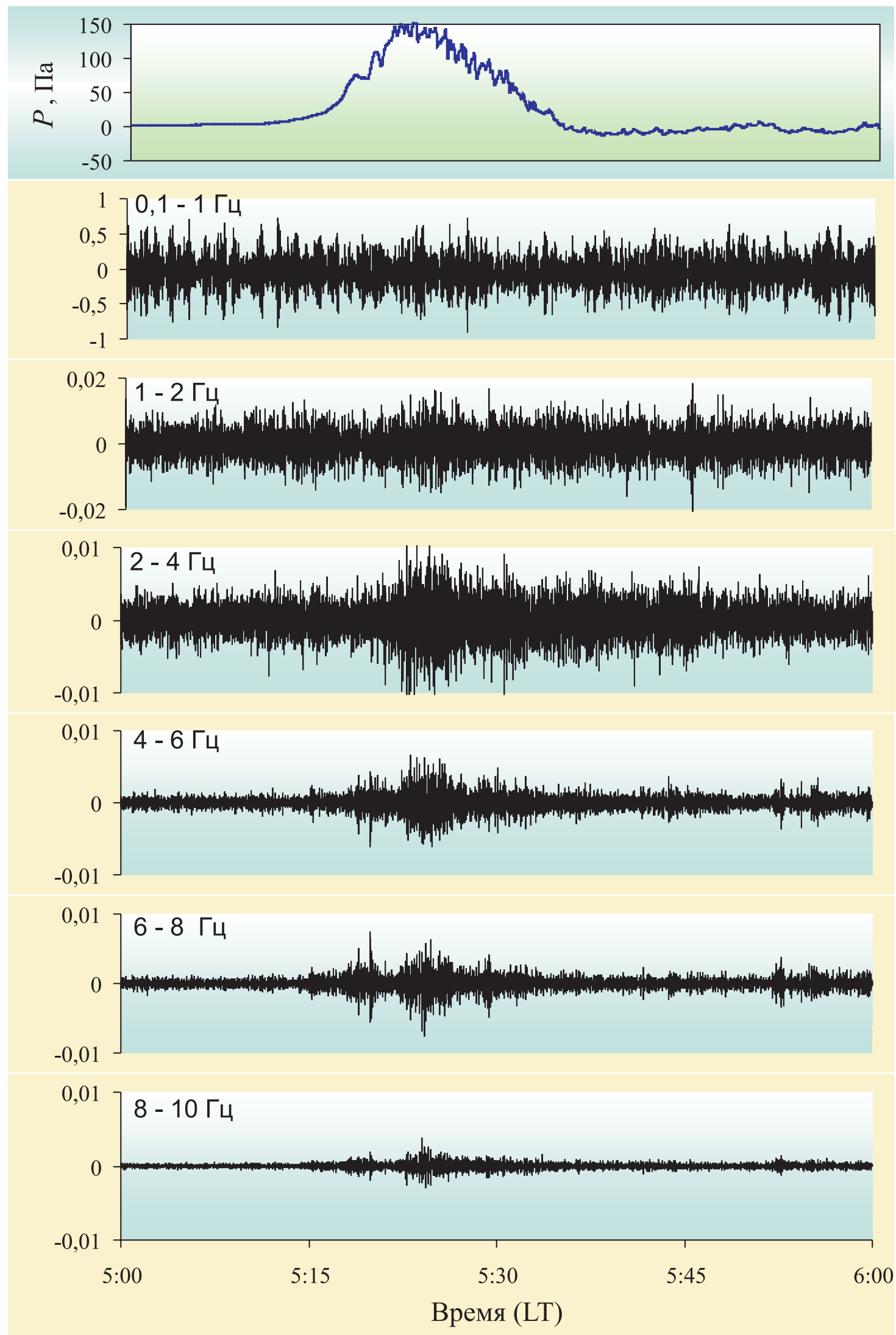

Рис. 15. Вариация сейсмического фона в мкм/с в разных частотных диапазонах (диапазон частот приведен в поле рисунков на шести нижних панелях) в период прохождения атмосферного фронта (вариация атмосферного давления $P$ приведена на верхней панели).

Fig. 15. Seismic background variations $(\mathrm{mcm} / \mathrm{sec})$ in various frequency ranges during frontal passages (top - variations of atmospheric pressure, $P$; six bottom panels - frequency ranges). 


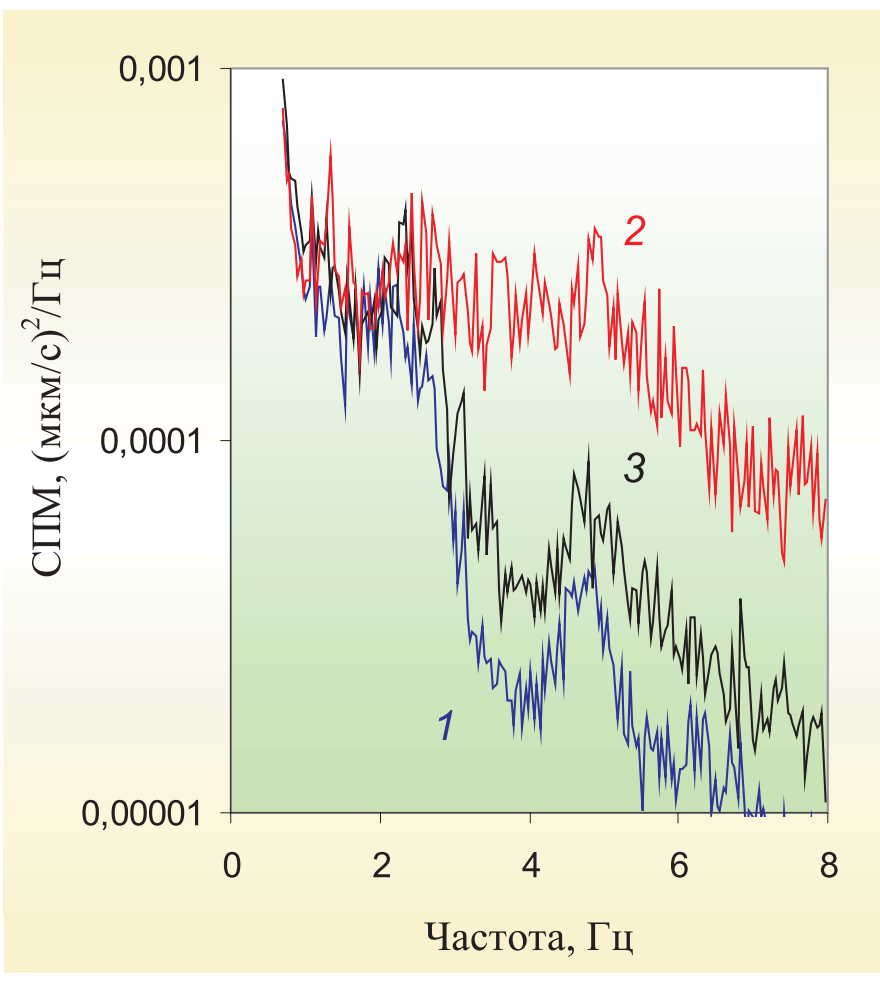

Рис. 16. Спектральная плотность мощности (СПМ) сейсмического фона до (1), в период (2) и спустя 15 мин после прохождения атмосферного фронта (3).

Fig. 16. Power spectral density of the seismic background before (1), during (2) and 15 min. after (3) the frontal passage.
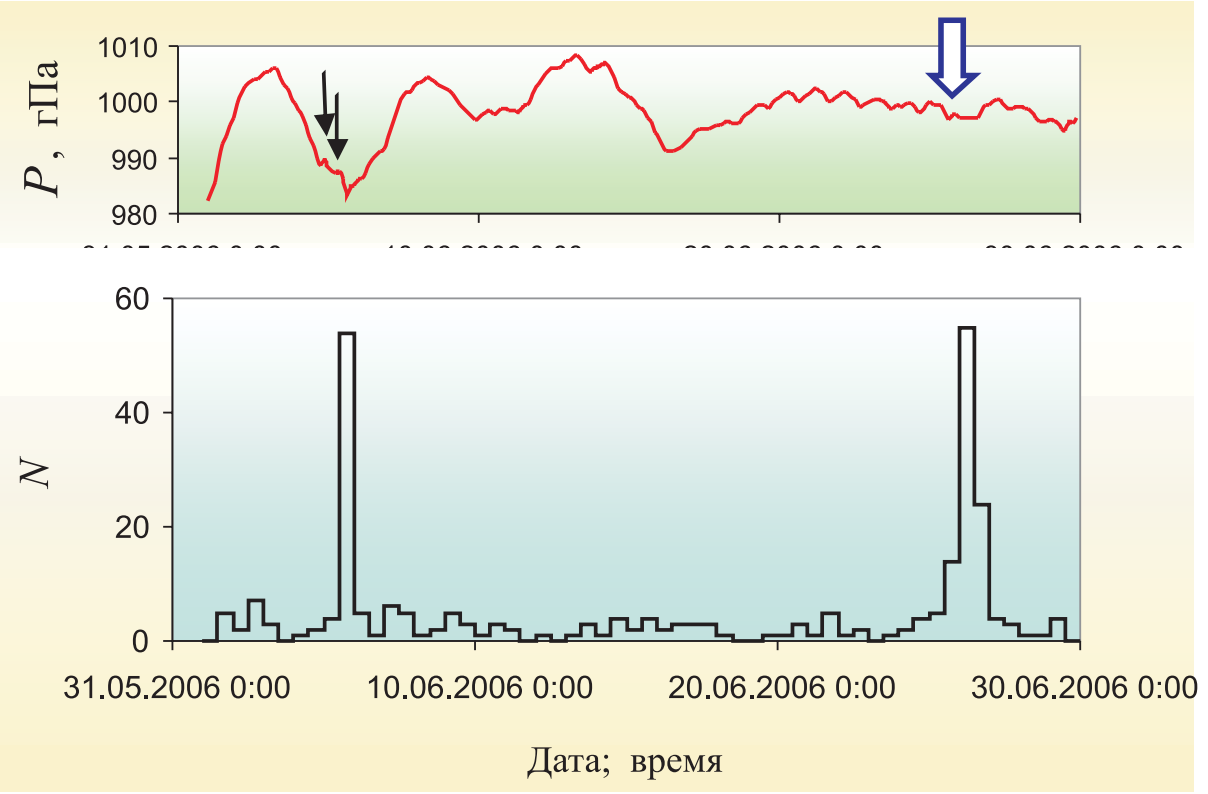

Рис. 17. Вариация интенсивности релаксационных процессов (нижняя панель: количество актов релаксации $N$ за период 6 час) в период прохождения атмосферного фронта (верхняя панель: вариация атмосферного давления $P$ ).

Стрелками обозначены времена прохождения атмосферных фронтов (незалитая стрелка - прохождение атмосферного фронта в период отсутствия циклонических процессов).

Fig. 17. Relaxation intensity variations during frontal passages. Top - variations of atmospheric pressure, $P$. Bottom - number of relaxation acts in the 6-hour period.

Arrows - time of frontal passages; white arrow - frontal passage in the absence of cyclonic processes. 
на амплитудные характеристики геофизических полей и их временные вариации.

В разломных зонах более ярко по сравнению с серединными участками структурных блоков земной коры проявляются процессы, связанные с обменом энергии между полями разной природы: эманационного поля радиоактивного радона - в электрическое поле приземного слоя атмосферы, а также барических вариаций в атмосфере - в микросейсмические колебания.

Специфическая внутренняя структура разломных зон, характеризующаяся повышенной раздробленностью горных пород и повышенной деформируемостью, определяет повышенную интенсивность преобразова- ния энергии между механическими колебаниями и электрическим и магнитным полями. В частности, нелинейные эффекты, сопровождающие распространение сейсмических волн через разломные зоны, приводят к преобразованию энергии сейсмических волн в энергию электромагнитных колебаний.

Полученные количественные зависимости можно рассматривать в качестве основы для установления природы и конкретных механизмов влияния разломных зон на геофизические поля разной природы.

Исследования выполнены при поддержке РФФИ (грант 14-05-00073).

\section{7. ЛИТЕРАTУРA / REFERENCES}

Adushkin V.V., Spivak A.A., 2006. Microseismicity and intensity of relaxation processes in the Earth's crust. Doklady Earth Science 408 (1), 671-673. http://dx.doi.org/10.1134/S1028334X06040362.

Adushkin V.V., Spivak A.A., 2007. Underground explosions. Publishing House "NAUKA”, Moscow, 576 p. (in Russian) [Адушкин В.В., Спивак А.А. Подземные взрывы. М.: Наука, 2007. 567 с.].

Adushkin V.V. Spivak A.A., Kishkina S.B., Loktev D.N., Solov'ev S.P., 2006. Dynamic processes in the system of interacting geospheres at the Earth's crust-atmosphere boundary. Izvestiya, Physics of the Solid Earth 42 (7), 567-584. http://dx.doi. org/10.1134/S1069351306070044.

Anisimova O.V., Koronovsky N.V., 2007. Lineaments in the central part of the Moscow syneclise and their relations to faults in the basement. Geotectonics 41 (4), 315-332. http://dx.doi.org/10.1134/S001685210704005X.

Gokhberg M.B., Morgunov V.A., Pokhotelov O.A., 1988. Seismo-electromagnetic phenomena. Publishing House "NAUKA", Moscow, 174 p. (in Russian) [Гохберг М.Б., Моргунов В.А., Похотелов О.А. Сейсмоэлектромагнитные явления. М.: Наука, 1988. 174 с.].

Gorbunova E.M., Ivanchenko G.N., Spivak A.A., 2002. Choice of the object for complex investigations of geodynamic and geophysical anomalies in zones of fault influence. In: Non-stationary processes in the upper and lower geospheres of the Earth. Publishing House of IDG RAS, Moscow, p. 114-129 (in Russian) [Горбунова Э.М., Иванченко Г.Н., Спивак A.А. Выбор объекта для проведения комплексных исследований геодинамических и геофизических аномалий в зонах влияния тектонических структур // Нестационарные процессы в верхних и нижних геосферах Земли. М.: ИДГ РАН, 2002. С. 114-129].

Ivanchenko G.N., 2012. Interpretation of the results of automated deciphering of the data of remote sensing for estimation of the modern geodynamic situation. Candidate's dissertation (Ph\&Mth). Institute of geospheres dynamics of RAS, Moscow, 130 p. (in Russian) [Иванченко Г.Н. Интерпретация результатов автоматизированного дешифрирования данных дистанционного зондирования при оценке современной геодинамической обстановки. Дис. ... канд. физ.мат. наук. М.: ИДГ РАН, 2012. 130 с.].

Kocharyan G.G., Spivak A.A., 2003. The dynamics of rock deformation. Publishing House “Akademkniga”, Moscow, 423 p. (in Russian) [Кочарян Г.Г., Спивак А.А. Динамика деформирования блочных массивов горных пород. М.: Академкнига, 2003. 423 с.].

Loseva T.V., Spivak A.A., Kuz'micheva M.Yu., 2012. A dipole model of generating electric pulses in relaxation processes in the Earth's Crust. Doklady Earth Science 442 (1), 159-162. http://dx.doi.org/10.1134/S1028334X12010278.

Makarov V.I., Dorozhko A.L., Makarova N.V., Makeev V.M., 2007. Modern geodynamically active platform zones. Geoecologiya (2), 99-100 (in Russian) [Макаров В.И., Дорожко А.Л., Макарова Н.В., Макеев В.М. Современные геодинамически активные зоны платформ // Геоэкология. 2007. № 2. С. 99-110].

Nesmeyanov S.A., 2004. Engineering geotectonics. Publishing House “NAUKA”, Moscow, 780 p. (in Russian) [Несмеянов C.A. Инженерная геотектоника. М.: Наука, 2004. 780 с.].

Nikolaev V.G., Garetskii R.G., Aizberg R.E., Kovkhuto A.M., 2002. Faults of the Moscow syneclise. Geotectonics 36 (6), 463-468.

Novik O.B., Ershov S.V., 2001. Electromagnetic and thermal signals from the depth. Publishing House "Krugly God", Moscow, 288 p. (in Russian) [Новик О.Б., Ершов С.В. Электромагнитные и тепловые сигналы из недр Земли. М.: «Круглый год», 2001. 288 с.].

Seminsky K.Zh., 2003. Internal structure of continental faults. Publishing House of SB RAS, GEO Branch, Novosibirsk, 293 p. (in Russian) [Семинский К.Ж. Внутренняя структура континентальных разломных зон. Новосибирск: Издво СО РАН, Филиал «Гео», 2003. 293 с.]. 
Seminsky K.Zh., 2012. Internal structure of fault zones: spatial and temporal evolution studies on clay models. Geodynamics \& Tectonophysics 3 (3), 183-194. http://dx.doi.org/10.5800/GT-2012-3-3-0070.

Seminsky K.Zh., Bobrov A.A., 2013. The first results of studies of temporary variations in soil-radon activity of faults in Western Pribaikalie. Geodynamics \& Tectonophysics 4 (1), 1-12. http://dx.doi.org/10.5800/GT-2013-4-1-0088.

Sobolev G.A., 1993. Faundations of earthquake’s prediction. Publishing House “NAUKA”, Moscow. 312 p. (in Russian) [Соболев Г.А. Основы прогноза землетрясений. М.: Наука, 1993. 312 с.].

Sobolev G.A., Demin V.M., 1980. Mechanoelectrical phenomena in the Earth. Publishing House "NAUKA”, Moscow. 215 p. (in Russian) [Соболев Г.А., Демин В.M. Механоэлектрические явления в Земле. М.: Наука, 1980. 215 с.].

Soloviev S.P., Spivak A.A., 2009. Electromagnetic signals generated by the electric polarization during the constrained deformation of rocks. Izvestiya, Physics of the Solid Earth 45 (4), 347-355. http://dx.doi.org/10.1134/S1069351309040 077.

Spivak A.A., 2008. Structure of the faults as zones with heightened intensity of interactions between geospgeres. In: Geophysics of the interactions between geospheres. Publishing Houses “GEOS”, Moscow, p. 23-28 (in Russian) [Спивак A.A. Структура тектонических нарушений как зон повышенной интенсивности межгеосферных взаимодействий // Геофизика межгеосферных взаимодействий. М.: ГЕОС, 2008. С. 23-28].

Spivak A.A., 2010. The specific features of geophysical fields in the fault zones. Izvestiya, Physics of the Solid Earth 46 (4), 327-338. http://dx.doi.org/10.1134/S1069351310040051.

Spivak A.A., 2011. Rigidity of the fault zones in the Earth's crust estimated from seismic data. Izvestiya, Physics of the Solid Earth 47 (7), 600-609. http://dx.doi.org/10.1134/S1069351311060061.

Spivak A.A., Kishkina S.B., 2004. The use of microseismic background for the identification of active geotectonic structure and determination of geodynamic characteristics. Izvestiya, Physics of the Solid Earth 40 (7), 573-586.

Spivak A.A., Kozhukhov S.A., 2004. Spatiotemporal nature radon variations in the subsoil atmosphere. Doklady Earth Science 395 (2), 223-225.

Spivak A.A., Kozhukhov S.A., Sukhorukov M.V., Kharlamov V.A., 2009. Radon emanation as an indicator of the intensity of intergeospheric interactions at the Earth's crust-atmosphere interface. Izvestiya, Physics of the Solid Earth 45 (2), 118-133. http://dx.doi.org/10.1134/S1069351309020037.

Spivak A.A., Shuvalov V.V., 2011. Variations of the fault filtration properties during solid tide. In: Local and global manifestations of influence on the geospheres. Publishing House "GEOS", Moscow, p. 30-42 (in Russian) [Спивак А.А., Шувалов В.В. Вариации фильтрационных свойств тектонических нарушений в результате твердого прилива // Локальные и глобальные проявления воздействий на геосферы. М.: ГЕОС, 2008. С. 30-42].

Spivak A.S., Tzvetkov V.M., 2009. A new model of the zonal structure of fractures. Doklady Earth Science 424 (1), 151-154. http://dx.doi.org/10.1134/S1028334X09010322.

Yudakhin F.N., Schukin Yu.K., Makarov V.I., 2003. Depth structure and modern geodynamic processes in lithosphere of Eastern-European platform. Publishing House of UralB RAS, Ekateringburg, 299 p. (in Russian) [Юдахин Ф.Н., Щукин Ю.К., Макаров В.И. Глубинное строение и современные геодинамические процессы в литосфере ВосточноЕвропейской платформы. Екатеринбург: Уро РАН, 2003. 299 с.].

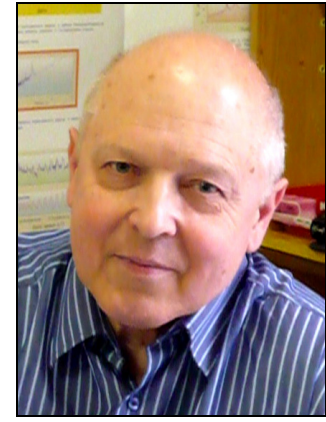

Спивак Александр Александрович, докт. физ.-мат. наук, профессор

Институт динамики геосфер РАН

119334, Москва, Ленинский проспект, 38, корпус 1, Россия

Тел.: 89168474199; $\$ e-mail: spivak@idg.chph.ras.ru, Aaspivak100@gmail.com

Профессор кафедры теоретической и экспериментальной физики геосистем

Московского физико-технического института (государственного университета)

Spivak, Alexander A., Doctor of Physics and Mathematics, Professor

Institute of Geosphere Dynamics RAS

Building 1, 38 Leninsky Prospect, Moscow 119334, Russia

Tel.: 89168474199; \ e-mail: spivak@idg.chph.ras.ru, Aaspivak100@gmail.com

Professor of the Chair of Theoretical and Experimental Physics of Geosystems,

Moscow Physics and Technology Institute (State University) 